\title{
The framing effect and breast cancer treatment options: Do individual characteristics play a role?
}

Kelly L. Schuller

West Virginia University

Follow this and additional works at: https://researchrepository.wvu.edu/etd

\section{Recommended Citation}

Schuller, Kelly L., "The framing effect and breast cancer treatment options: Do individual characteristics play a role?" (2006). Graduate Theses, Dissertations, and Problem Reports. 4265.

https://researchrepository.wvu.edu/etd/4265

This Dissertation is protected by copyright and/or related rights. It has been brought to you by the The Research Repository @ WVU with permission from the rights-holder(s). You are free to use this Dissertation in any way that is permitted by the copyright and related rights legislation that applies to your use. For other uses you must obtain permission from the rights-holder(s) directly, unless additional rights are indicated by a Creative Commons license in the record and/ or on the work itself. This Dissertation has been accepted for inclusion in WVU Graduate Theses, Dissertations, and Problem Reports collection by an authorized administrator of The Research Repository @ WVU.

For more information, please contact researchrepository@mail.wvu.edu. 
The Framing Effect and Breast Cancer Treatment Options:

Do Individual Characteristics Play a Role?

\author{
Kelly L. Schuller \\ Dissertation submitted to the \\ Eberly College of Arts and Sciences \\ in partial fulfillment of the requirements \\ for the degree of \\ Doctor \\ of \\ Philosophy
}

Committee Members:

Chair: JoNell Strough, Ph.D.

Barry Edelstein, Ph.D.

Julie Hicks Patrick, Ph.D.

Katherine Karraker, Ph.D.

Bei Wu, Ph.D.

Department of Psychology

Morgantown, West Virginia

2006

Keywords: Breast cancer, decision making, framing effect, treatment 


\begin{abstract}
The Framing Effect and Breast Cancer Treatment Options:

Do Individual Characteristics Play a Role?
\end{abstract}

Kelly L. Schuller

The effect of frame, or the way in which options are worded, has been shown to influence decisions in many domains; however, the literature lacks studies that examine the effect of age and other individual characteristics on susceptibility to the framing effect. Sixty-eight collegeaged women $(M$ age $=19.10$ years, $S D=1.54)$ and sixty-six women over the age of 60 years $(M$ age $=70.76$ years, $S D=7.10$ ) were presented with breast cancer vignettes that varied by frame (i.e., gains option worded in terms of number of women who would be cured and loss option worded in terms of number of women who would die) and degree of risk involved (i.e., risk averse versus risk seeking). Tversky and Kaheman's classic Asian disease design was adapted to create the breast cancer vignette. Participants rated the likelihood of choosing the risk-averse or the risk-seeking treatments. The influence of individual characteristics (age, experience with breast cancer, cognitive ability, cognitive processing, sensation seeking, and need for cognition) on treatment decisions was examined. When presented with the negative frame, older women made riskier decisions than did women presented with the positive frame. Frame, however, did not influence younger women's decisions. Experience with breast cancer (personal and vicarious), crystallized and fluid intelligence (as assessed by the Kaufman Brief Intelligence Test), analytical versus heuristic cognitive processing (as assessed by the Rational Experiential Inventory), and sensation seeking (as assessed by the Impulsive Sensation Seeking Scale) were not associated with treatment decisions. Women lower in need for cognition made riskier decisions than did women higher in need for cognition, but that did not vary by frame. The age $\mathrm{x}$ frame interaction found using with the breast cancer vignette was also shown using general cancer and non-cancer vignettes. This indicates the interaction of age and frame is generalizable to domains other than breast cancer. Thus, the way in which options are worded influences older women's decisions, which may influence outcomes, particularly in the domain of health. Results can be used to inform health professionals on the best way to present treatment information to patients. 


\section{Acknowledgments}

I would like to thank my committee members: JoNell Strough, Ph.D., Julie Hick Patrick, Ph.D., Barry Edelstein, Ph.D., Katherine Karraker, Ph.D., and Bei Wu, Ph.D. I would especially like to thank JoNell Strough for being a wonderful mentor and offering so much guidance throughout my graduate school career. I would like to thank the Eberly College of Arts and Sciences and the Department of Psychology for funding my project. Finally, I would like to thank my mom, Terry Snyder, and my husband, Kevin Schuller, for always being there and offering support. I couldn't have done it without you! 


\section{TABLE OF CONTENTS}

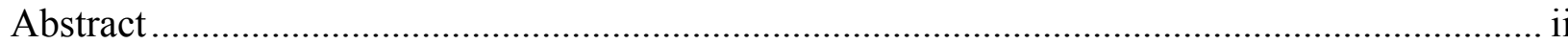

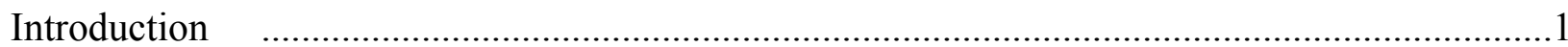

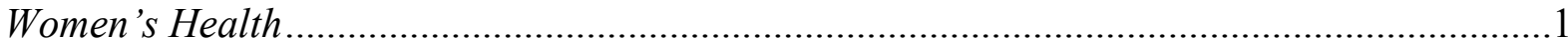

Breast Cancer Decision Making ......................................................... 2

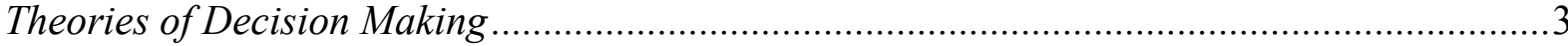

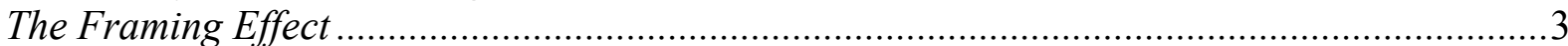

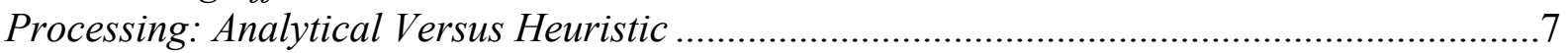

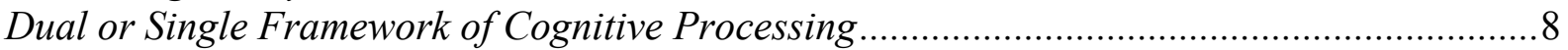

Cognitive Processing as an Individual Characteristic or Situational Variable .......................... 8

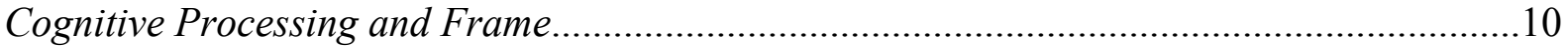

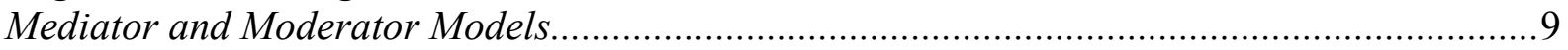

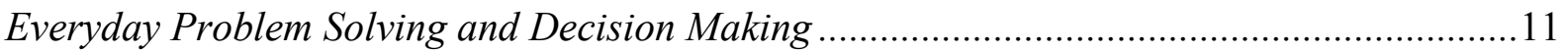

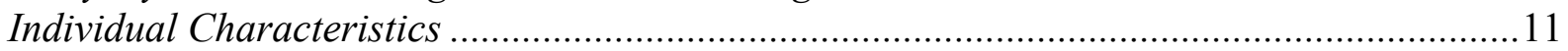

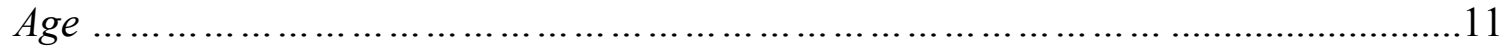

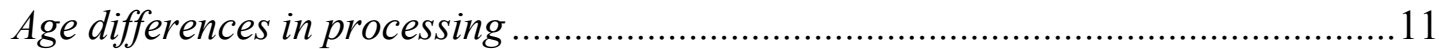

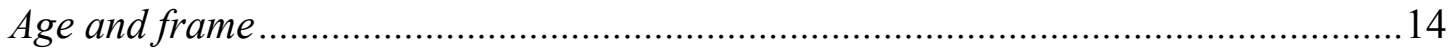

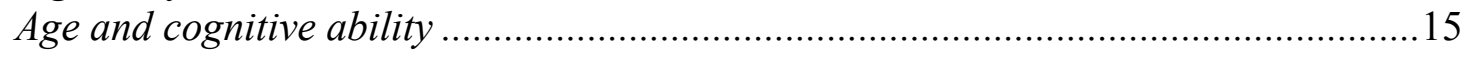

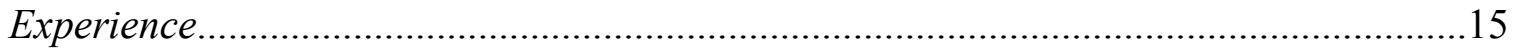

Cognitive Processing and Experience/Expertise ………...............................................16

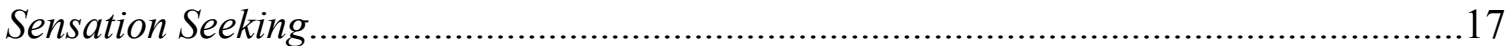

Analytical Processing and Need for Cognition .............................................................18

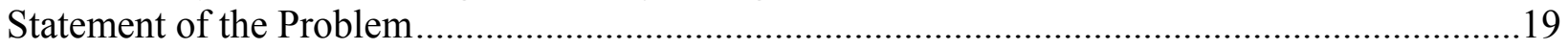

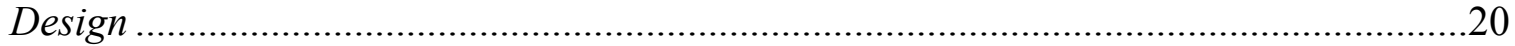

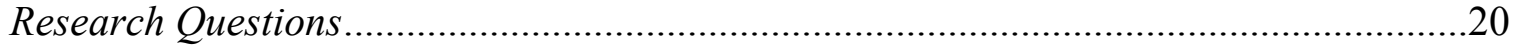

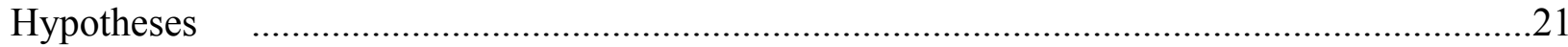

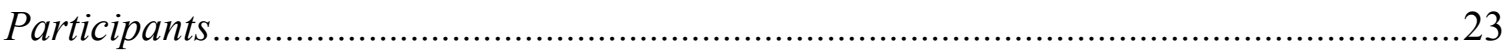

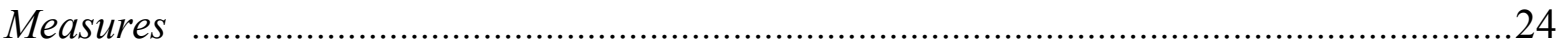

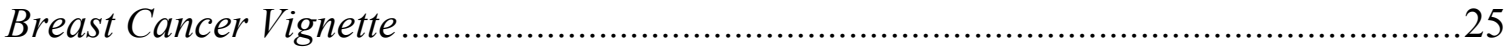

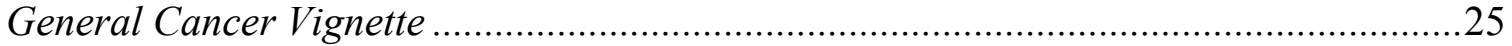

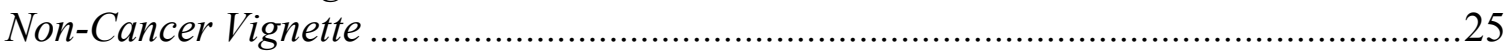

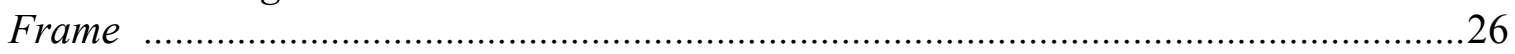

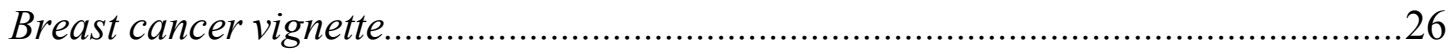

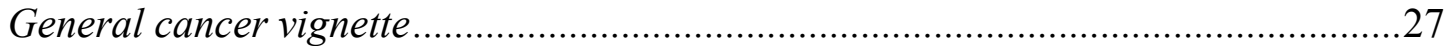

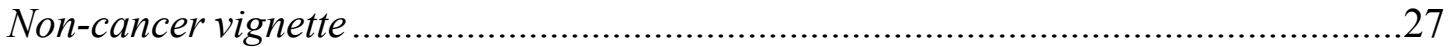

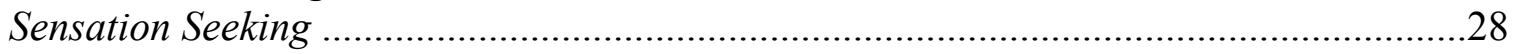

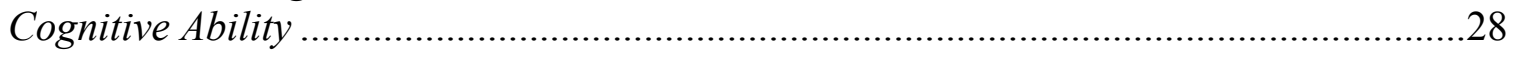

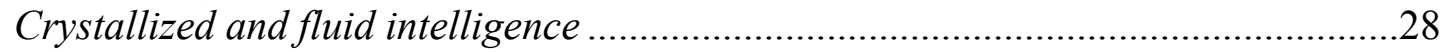

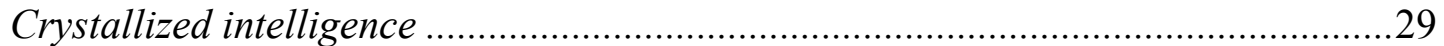

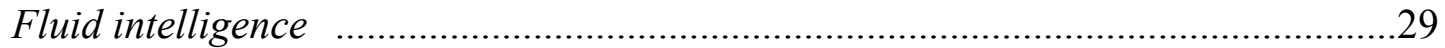

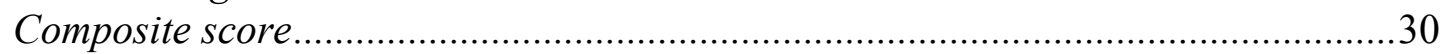

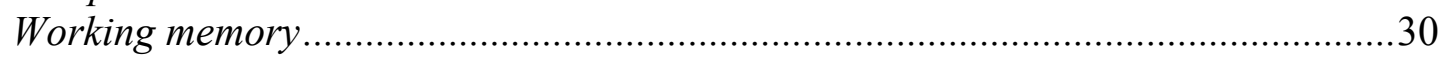

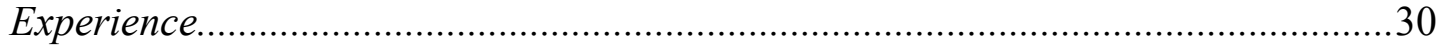

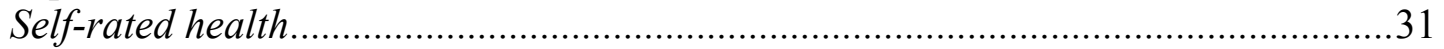

Type of cognitive processing and need for cognition ..............................................31 


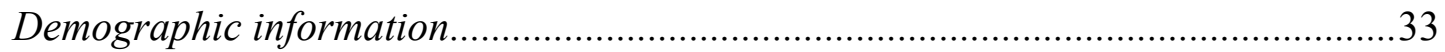

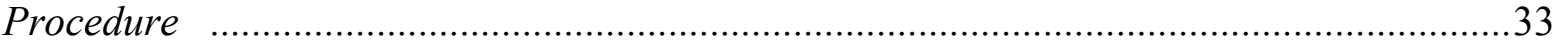

Results

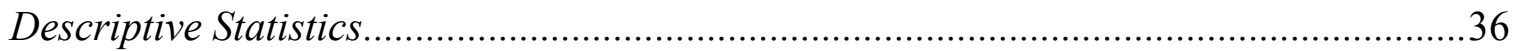

The Influence of Age and Frame on Treatment Choice.....................................................37

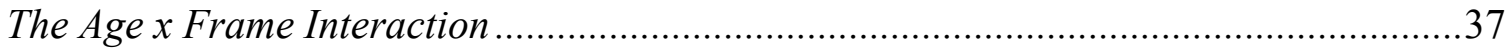

Cognitive Processing as a Mediator ................................................................................37

Individual Characteristics as Moderator Variables .....................................................39

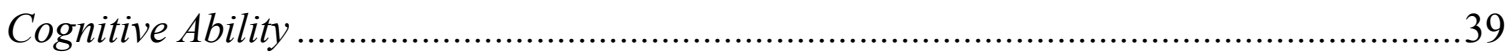

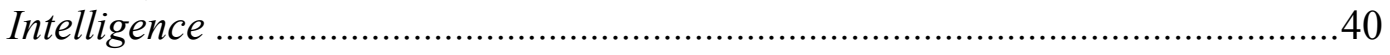

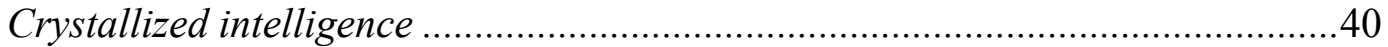

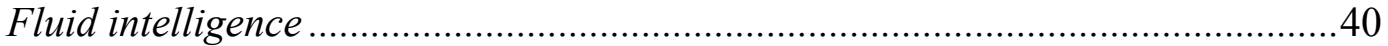

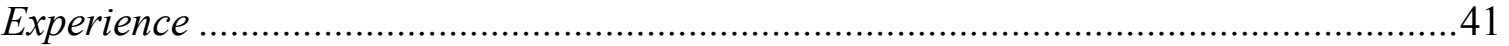

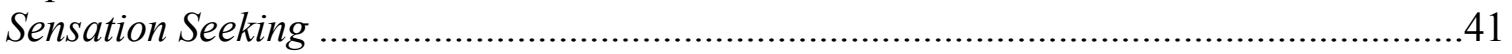

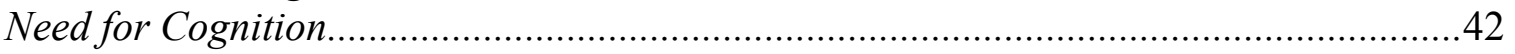

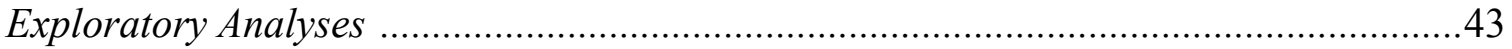

Generalizability ....................................................... 43

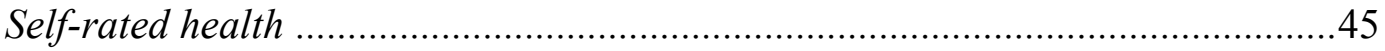

Comfort speaking to physician ..............................................45

Comfort seeking second opinion ............................................45

Cognitive processing and treatment choice .....................................................46

The influence of age and frame on cognitive processing ....................................46

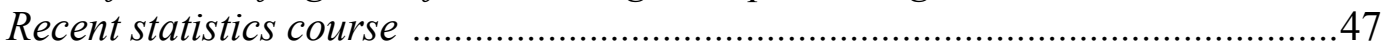

Decisions for breast cancer, general cancer, and non-cancer ....................47

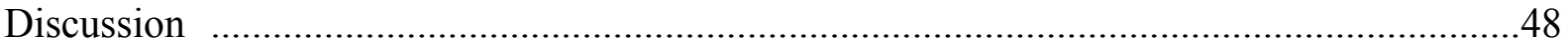

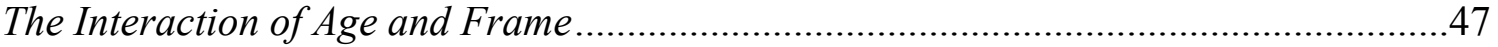

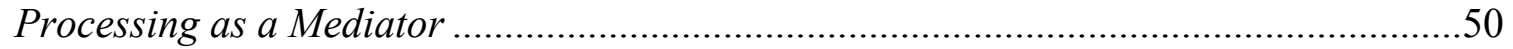

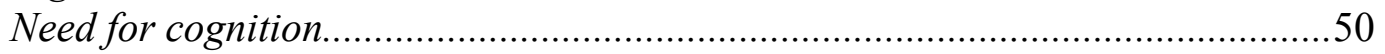

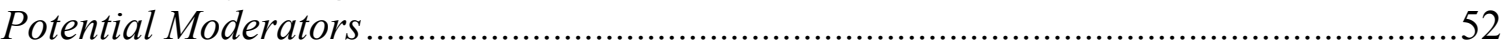

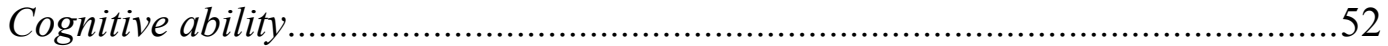

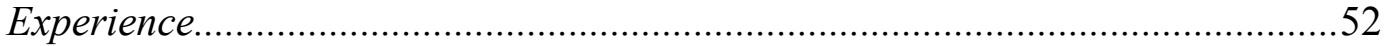

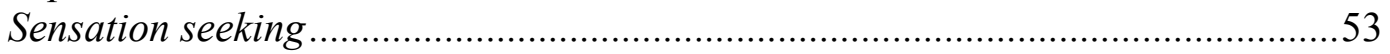

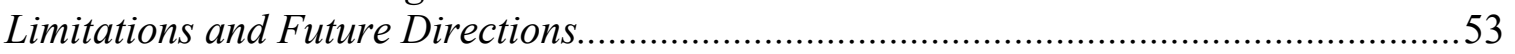

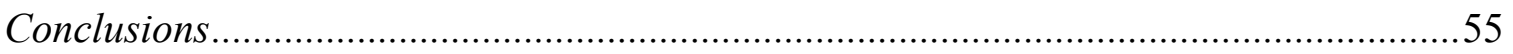

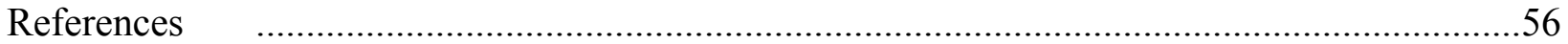

Table 1: Cognitive Processing: Heuristic Versus Analytical .....................................................66

Table 2: Descriptive Statistics for Women Who Did and Did Not Participate in the NIH-Funded

Study ..........................................................................67

Table 3: Experience with Breast Cancer for Women From and Not From the NIH Study.........68

Table 4: Descriptive Information for Older and Younger Women ........................ 69

Table 5: Experience with Breast Cancer for Older and Younger Women .................. 70

Table 6: Summary of Hierarchical Regression of Age and Frame on Treatment Choice .... 71

Table 7: Summary of Separate Linear Regressions of Cognitive Ability, Experience, and Sensation Seeking Predicting Treatment Choice............................... 72 
Table 8: Summary of Hierarchical Regression of Frame and Need for Cognition on Treatment Choice....................................................................... 73

Table 9: Older and Younger Women's Decisions in All Domains.............................................74

Table 10: Summary of Separate Linear Regressions of Cognitive Processing, Need for Cognition, and Faith in Intuition on Treatment Choice................................... 75

Table 11: Frequencies of Treatment Decision Ratings for Total sample and Younger and Older Women........................................................................... 76

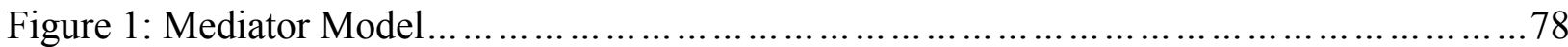

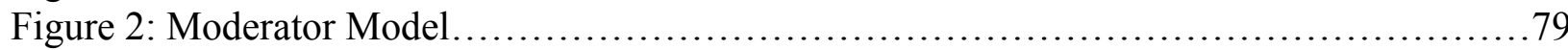

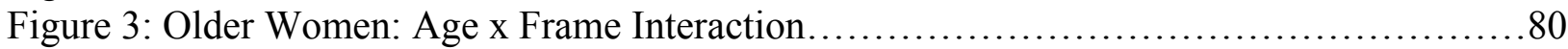

Figure 4: Mediated Moderation Model................................................. 81

Figure 5: Older Women's Decisions in Each Domain....................................... 82

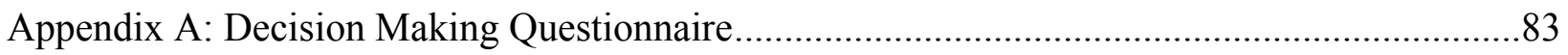


The Framing Effect and Breast Cancer Treatment Options:

Do Individual Characteristics Play a Role?

Research that examines medical decision making indicates that the way in which a treatment option is framed (worded either positively or negatively) influences peoples' choice of treatment (McNeil, Pauker, Sox, \& Tversky, 1982; Rybash \& Roodin, 1989; Tversky \& Kahneman, 1981). The degree to which frame impacts treatment decision may be influenced by individual difference characteristics. One individual characteristic that may be important is age. Age has been shown to influence the ways in which individuals process information and reason (Klacyznski \& Robinson, 2000); however, few studies examine the impact of age and frame on medical decision making. Other individual characteristics, such as experience, cognitive ability, sensation seeking, need for cognition, and type of cognitive processing may also influence medical decision making. The literature lacks empirical studies that examine how the way treatment options are framed in combination with individual characteristics influence the decisions that women make when dealing with breast cancer. The current study adds to the literature by examining these variables as they relate to women's decisions when presented with a vignette dealing with breast cancer.

\section{Women's Health}

The issue of women's health has gained the attention of both policy makers and researchers. According to the US Census (2003), fifty-one percent of the total US population is female; however, the proportions of the sexes vary by age. There are more males than females in the younger age groups and consecutively more females than males with age. Breast cancer is an important health concern that impacts both females and males; however, breast cancer is about 100 times more likely to affect females (American Cancer Society, ACS, 2006). Many women 
will be influenced by breast cancer either personally or through someone they know. According to the American Cancer Society, breast cancer is the most common form of cancer in women, following skin cancer. Over 2 million women in the United States have breast cancer. Among women's cancer-caused deaths, breast cancer ranks second only to lung cancer. Approximately 40,410 women will die from the disease in the year 2006. Breast cancer strikes women of all ages and races; however, the chances of getting breast cancer increase with age. At age 30 women have a one in 2525 risk of getting breast cancer, by age 40 this increases to one in 217 and one out of 24 by 60 years of age. The chance of a woman having breast cancer at some time during her lifetime is 1 in 7; the chance of a women dying from breast cancer is 1 in 33 (ACS).

\section{Breast Cancer Decision-Making}

The literature that examines medical decision-making is expansive. Research has examined decision making related to many different types of cancer, including prostate cancer (Steginga \& Occhipinti, 2006), lung cancer (Sharf, Stelljes, \& Gordon, 2005), cervical cancer (White, Wearing, \& Hill, 1994), skin cancer (Rasmussen, 2005), and breast cancer (Meyer, Russo, \& Talbot, 1995). Women diagnosed with breast cancer face a variety of decisions, including which treatment options are best for them. There are many treatment options available (www.breastcancer.org, 2006). Decisions must be made whether to choose conservative or radical treatment options. Conservative treatment options include lumpectomy, whereas, radical treatment options include single or double mastectomy. In addition, chemotherapy, radiation therapy, or hormonal therapies are often part of the treatment regimen. Information about treatment options is often presented to patients by a physician or someone on the medical staff. In addition, women may be given literature on the treatment options available and what is 
involved with each option. Many factors, such as how the information is presented, may influence the decision-making process.

\section{Theories of Decision Making}

Decision making can be rational or irrational. Von Neumann and Morgenstern's Expected Utility Theory (1947) describes several axioms, or principles, for rational decision making. One principle, invariance, states "the preference order between prospects should not depend on the manner in which they are described" (Kahneman \& Tversky 1984). Therefore, according to Expected Utility Theory, when making decisions, a rational individual's choice should not be influenced by the way in which the options are worded or framed. However, research indicates that the way in which a message is framed or worded in terms of either gains or losses influences peoples' decisions (McNeil et al., 1982; Rybash \& Roodin, 1989; Tversky \& Kahneman, 1979). Tversky and Kahneman's Prospect Theory describes conditions which induce individuals to make irrational choices. According to Prospect Theory, people "overweight outcomes that are considered certain, relative to outcomes that are merely probable" (Tversky \& Kahneman, p. 265). People tend to be risk averse (i.e., choose the sure thing) when the problem is framed, or worded, positively in terms of gains, whereas people are risk seeking (i.e., choose the risky option) when the problem is framed, or worded, negatively in terms of losses.

\section{The Framing Effect}

In the classic framing effect study, Tversky and Kahneman (1979) presented participants with the hypothetical vignette below which described an ambiguous Asian disease. 
Imagine that the U.S. is preparing for the outbreak of an unusual Asian disease, which is expected to kill 600 people. Two alternative programs to combat the disease have been proposed.

In Tversky and Kahneman's (1979) study, participants were asked to choose between treatment options. Treatment options contained the same expected outcome in terms of risk; however, options were presented as either gain-framed or loss-framed. In the gain-framed condition, the treatment options were described as the number of lives that would be saved; in the loss-framed condition, treatment options were described as the number of lives that would be lost. The participants were asked to assume that the exact scientific estimates of the consequences of the programs are as follows:

Gain-framed condition:

If program A is adopted, 200 people will be saved.

If program $B$ is adopted, there is a $1 / 3$ probability that 600 people will be saved, and a $2 / 3$ probability that no people will be saved.

Loss-framed condition:

If program $\mathrm{A}$ is adopted, 400 people will die.

If program $B$ is adopted, there is a $1 / 3$ probability that nobody will die, and a $2 / 3$ probability that 600 people will die.

Tversky and Kahneman (1979) found that a framing effect occurred. That is, although the outcomes of the positive gain-framed and negative loss-framed options are statistically equivalent, the way in which the options were worded affected the treatment decision. In the 
gain-framed condition, participants chose the less risky option or the "sure thing" (program A). In the loss-framed condition, participants chose the more risky option (program B).

The framing effect is a well established phenomenon that has been examined using different designs in multiple domains: the Asian disease design (the classic study design presented above), the gambling design, the tax evasion design, the clinical reasoning design, the bargaining design, the message compliance design, the escalation of commitment design, the evaluation of objects design, and the game-theory design (see Kuhberger, 1998 for review). Kuhberger conducted a meta-analysis of 136 empirical studies that used various designs to examine the framing effect. Results of the meta-analysis showed that, in general, the effect of frame was small to moderate; however, the calculation of effect sizes was difficult because many of the studies did not report effect sizes. Kuhberger also stated that there was a larger effect of frame when using the Asian disease design as compared to any of the other designs. In the current study, the classic Asian disease design was adapted for use with medical decisions about breast cancer. Thus, it was expected that there would be an effect of frame on treatment decision.

Research shows that the way information is framed influences decisions in many different areas, including business decision making (Kuvaas \& Kaufmann, 2004), gambling decisions (Loke \& Tan, 1992), marketing research (Block \& Keller, 1995; Olekalns \& Frey, 1994), and medical decision making (Rothman \& Salovey, 1997). The influence of frame on medical decision making has consistently been shown in the literature and persists even when a single person is presented with both frames (Frisch, 1993; Reyna \& Brainerd, 1991). In a study that examined the effect of frame on 133 women's (ages 40 and older) decisions to undergo a preventative mammography, Banks and colleagues (1995) found that women were more likely to choose to undergo a mammography when presented with a video message that was negatively 
framed (i.e., stressing the risks of not getting a mammography) as compared to women who were presented with a video message framed positively (i.e., stressing the benefits of getting a mammography). Similarly, Meyerowitz and Chaiken (1987) found that young adult women presented with a pamphlet that emphasized the risks of not performing self-breast exams (i.e., loss-framed information) reported that they would more likely to perform a self-breast examination as opposed to women presented with: (1) a pamphlet that emphasized the benefits of performing self-breast exams (i.e., gain-framed information), (2) a pamphlet that did not present either the benefits or risks, or (3) no pamphlet at all. Malloy, Wigton, Meeske, and Tape (1992) examined the influence of frame on older adults' decisions about medical intervention (i.e., lifesustaining treatment). Results showed that individuals presented with a negative description of the treatment (i.e., "machine that controls your breathing", p. 145) were less likely to choose the intervention as compared individuals presented with a neutral frame (i.e., "breathing by machine", p. 145), or positive frame (i.e., “device to help you breathe”, p.145). Together, these results indicate that the way in which a medical decision is framed, particularly when framed negatively, or in terms of losses, influences choices to undergo preventative therapy and treatment.

In the current study, the Asian disease design of Tversky and Kahneman (1979) was used to examine the framing effect in women's medical decision making when dealing with breast cancer. Positive frame was presented as the number of women who would be cured and the negative frame was presented as the number of women who would die. Consistent with Prospect Theory, it was expected that women presented with the positive frame would be more likely to be risk-averse (i.e., more likely to choose the "sure thing"), whereas women presented with the 
negative frame would be more likely to be "risk-taking" (i.e., more likely to choose the risky option).

\section{Processing: Analytical versus Heuristic}

An important aspect to consider when examining the influence of frame on decision making is the different types of cognitive processing in which individuals engage. Various terms have been applied to these types of processing: experiential and rational (Epstein, Lipson, Holstein, \& Hub, 1992), systematic and heuristic (Eagly \& Chaiken, 1993), intuition and reasoning (Kahneman, 2003), and analytical and heuristic (Finucane, et al., 2002; Klaczynski \& Robinson, 2000; Park, 1999; see Table 1). The terms analytical and heuristic processing are used in this report because the terms are most common in the literature.

Analytical processing involves "in-depth" mental processing, that is, "analytical processing is consciously controlled, effortful, and relies on abilities that are frequently believed to reflect cognitive maturity" (Klaczynski \& Robinson, 2000, p. 400; see Table 1). Analytical processing is more likely to occur when the person is highly motivated or when the decision, or the consequence of the decision, is very important (Klaczynski \& Robinson).

In contrast, heuristic processing involves the use of mental shortcuts to make decisions quickly and often efficiently. Heuristic processing involves less "in-depth" mental processing than does analytical processing, that is, heuristic system processing is preconscious, rapid, and effortless (Klaczynski \& Robinson, 2000, p. 400; see Table 1). Heuristic processing is more likely to occur when the decision is not very important or when the person is not able or motivated to invest cognitive energy to the decision-making process (Finucane, et. al., 2002), or when the person is an expert in the area of the decision (Johnson, 1981). The role of expertise in 
understanding the decision-making process is developed in greater detail in the cognitive processing and experience/expertise section.

\section{Dual or Single Framework of Cognitive Processing}

In the literature described above, cognitive processing is viewed as two distinct systems (i.e., analytical versus heuristic). This is known as the dual processes, or "dualist" approach (Eagly \& Chaiken, 1993; Epstein, Lipson, Holstein, \& Hub, 1992; Finucane, et al., 2002; Kahneman, 2003). The dual process approach describes processing as two independent but interactive systems. One system, heuristic processing, is based on intuition and is implicit (i.e., without awareness), whereas, the other system, analytical processing, is based on logical reasoning and is explicit (i.e., deliberate and with awareness). Another approach views cognitive processing as a single framework (Hammond, 1996; Oberauer, 2000; Osman, 2004). According to the single framework approach, cognitive processing moves along a continuum, with heuristic reasoning at one end and analytical reasoning at the other. Although recent literature emphasizes the dual process approach, Hammond argues that a single framework approach is advantageous because it "accommodates a broader range of processing within a single-system framework" (Osman, p. 993). The current study examines cognitive processing as both a single framework (i.e., overall cognitive processing denoted "cognitive processing") and as dual processes (i.e., analytical processing, denoted "need for cognition", and heuristic processing, denoted "faith in intuition").

\section{Cognitive Processing as an Individual Characteristic or Situational Variable}

In addition to viewing cognitive processing as a continuum or dual processes, cognitive processing can be viewed as either an individual characteristic that is stable across time or a variable that depends on the situation. For example, an individual's tendency, or need, to engage 
in effortful thinking (i.e., analytical processing) is referred to as an individual's need for cognition (Cacioppo \& Petty, 1982). In general, this is often described as a personality trait that is fairly stable across time. In contrast, literature from social psychologists who conduct research on persuasion view cognitive processing, or the use of analytical versus heuristic reasoning as dependent upon the situation (Chaiken, 1987; Petty \& Cacioppo, 1986). For example, if an individual is motivated, he or she may engage in analytical processing. However, if the individual is not motivated, he or she may engage in heuristic processing.

\section{Cognitive Processing and Frame}

The influence of the way in which a message is worded, or framed, and the type of processing in which an individual engages could work together to impact decision making in various ways. According to Maheswaran and Meyers-Levy (1990), the effects of framing on message persuasiveness can be explained by Eagly and Chaiken's (1993) Heuristic-Systematic Model (HSM). According to HSM, negatively framed information is "non-normative", and therefore not as expected as positively framed information. Thus, when an individual engages in analytical processing, negatively framed messages should be more persuasive than positively framed messages. Maheswaran and Meyers-Levy argue that individuals more readily accept positively worded versus negatively worded information, therefore, when an individual engages in heuristic processing, positively framed messages should be more persuasive than negatively framed messages. According to Kahneman (2003), when individuals engage in analytical processing and are presented with both frames, they are more likely to recognize the relationships between framed options and answer consistently for both positively and negatively framed options. Thus, when individuals engage in analytical processing, the frame of the message should not impact the decision. In contrast, the frame, or way in which treatment 
options are presented, could influence decisions when an individual relies on heuristic processing. Thus, in the current study, individuals who rely on heuristic processing (i.e., those with high faith in intuition) may be influenced by the framing of the treatment options whereas individuals who rely on analytical processing (i.e., those with high need for cognition) may not be influenced by frame.

\section{Mediator and Moderator Models}

Individual characteristics, such as those described below, may function as mediator or moderator variables. A mediator variable is a variable that accounts for, or explains the mechanism by which a relationship between a predictor and a criterion variable occurs (Holmbeck, 1997). In order for a variable to function as a mediator it must meet the following criteria: "a) variations in levels of the independent variable significantly account for variations in the presumed mediator (see Path $a$ in Figure 1), b) variations in the mediator significantly account for variations in the dependent variable (see Path $b$ in Figure 1), and c) when Paths $a$ and $b$ (see Figure 1) are controlled, a previously significant relationship between the independent and dependent variables is no longer significant, or decreases (as indicated by the standardized $B$ weights; see Path $c$ in Figure 1)" (Baron \& Kenny, 1986, p. 1176).

A moderator is a variable that influences that strength or direction of the relationship between a predictor variable and a criterion variable (Baron\& Kenny). In order for a variable to function as a moderator it must meet the following criteria: a) the predictor must be significantly related to the criterion variable (see Path $a$ in Figure 2), b) the moderator must be significantly related to the criterion variable (see Path $b$ in Figure 2), and c) the predictor x moderator interaction must be significantly related to the criterion variable (see Path $c$ in Figure 2). 


\section{Everyday Problem Solving and Decision Making}

The everyday problem-solving literature that addresses how individual difference characteristics influence the problem-solving process may provide insight on the factors that influence decision making. There is a large amount of research that examines everyday problem solving (see Thorton \& Dumke, 2005 for review). Problem solving can be viewed as part of the decision-making process. Problem solving involves the presentation of a problem and the generation of various strategies to solve that problem. Decision making can be viewed as the final product of problem solving in that it involves evaluating the possible strategies or options and selecting one to use (Finucane, et al., 2002). In a meta-analysis of age differences in everyday problem solving and decision making, Thorton and Dumke (2005) found that outcomes in the everyday problem-solving literature were not significantly different from those in the decision-making literature. Thus, one can draw information from the everyday problem-solving literature when examining the decision-making process.

\section{Individual Characteristics}

Age

Age differences in processing. Age has been shown to influence everyday problem solving and decision making. A recent meta-analysis that examined age differences in everyday problem solving and decision making from laboratory studies showed that older adults had poorer everyday problem-solving/decision-making effectiveness than did young adults and middle-aged adults (Thorton \& Dumke, 2005). In addition, laboratory studies indicate older adults tend to seek out and use less information when solving problems and making decisions than do younger adults (Berg, Johnson, Meegan, \& Strough, 2003; Berg, Meegan, \& Klaczynski, 1999; Johnson, 1990; Meyer, Russo, \& Talbot, 1995). In an everyday decision-making task, 
Johnson (1993) found that older adults sought out less information and spent more time reviewing that information than did younger adults. Berg, Johnson, Meegan, and Strough used the same everyday decision-making task as did Johnson to examine collaborative everyday problem solving and also found that older adults took more time to make a decision than did younger adults. Cheng and Strough (2004) examined individual and collaborative problem solving and also showed that older adults took more time to complete the task than did younger adults.

Time to make decisions with the decision-making task used by Johnson (1993) and Berg and colleagues (2003) was measured in seconds. The difference in the time taken by older and younger adults in the problem-solving task by Cheng and Strough (2004) was approximately 11 minutes (see p.181). It is difficult to state that mere seconds or minutes actually influence decision making in a real-world decision-making situation, such as dealing with breast cancer. However, Meyer and colleagues (1995) examined age differences in decisions about breast cancer treatment with women who were actually diagnosed with breast cancer and found that older women sought out less information and took less time (measured in days) to make the decision than did younger adults. Laboratory studies suggest older adults take more time to make decisions than do younger adults (in terms of seconds or minutes). Real-world studies suggest older adults take less time to make decisions than do younger adults (in terms of days).

With age, individuals may be more likely to use heuristic processing as opposed to analytical processing, which could influence the way in which framing of information affects decisions. In this respect age differences may be a marker variable for the type of cognitive processing used. Thus, age differences in decisions may be mediated by type of cognitive processing (i.e., analytical or heuristic). 
Research also suggests that older adults process positive and negative information differently than do younger adults. Recent work by Carstensen and her colleagues (Lockenhoff \& Carstensen, 2004) suggests that older adults process positive information to a greater extent than do younger adults. When asked to choose between different health plans older adults spent more time reviewing the positive features of the plans; younger adults spent more time reviewing the negative features of the plans (Lockenhoff \& Carstensen). According to Maheswaran and Meyers-Levy’s (1990) application of the Heuristic-Systematic Model (Eagly \& Chaiken, 1993) to message framing, this could indicate that younger adults use a more analytical processing approach and focus on the negatives, whereas, older adults use a more heuristic processing approach and focus on the positives. Kahneman (2003) suggests that individuals who engage in heuristic processing are more influenced by the way in which a message is framed, or worded; therefore, perhaps older women will be more influenced by the frame than will younger women. One explanation for differences in the type of cognitive processing used with age is that heuristic processing uses less cognitive energy than analytical processing, which may compensate for age-related declines in cognitive capacity. According to the model of Selective Optimization with Compensation (Baltes \& Baltes, 1990), throughout the life span there are gains and losses in both cognitive and physical ability; however, with age, there tends to be more losses than gains. It is argued that declines in fluid intelligence, particularly working memory (Salthouse \& Babcock, 1991) lead to poorer decision making (i.e., seeking out less information, or taking longer) in older adults as compared to younger adults. Another explanation may be that individuals with a large amount of experience or expertise in an area may be more likely to engage in heuristic processing (Reyna \& Brainerd, 1995). However, the literature is inconsistent as to whether age differences in the decision-making process influence the quality of decisions. 
Real-world studies, such as that of Meyer, Russo and Talbot (1995), suggest the quality of older adults' decisions is about the same as that of younger adults (Meyer, Russo, \& Talbot, 1995). Thorton and Dumke's (2004) meta-analysis of laboratory studies suggests age-related declines in the quality of decisions. Therefore, it is not clear whether differences in processing of information with age necessarily translate to differences in the quality of outcomes, particularly when dealing with real-world situations.

Age and frame. Little research has examined how age and message frame influence medical decision making. Kuberger (1998) reviewed the research that examined the effect of frame to date and concluded that age may be an individual characteristic that would influence the effect of frame. Kuberger conducted the meta-analysis in 1998, since that time very little research has examined the influence of age on the framing effect. Mayhorn, Fisk, and Whittle (2002) examined the influence of age on medical and financial decisions and suggested that there are minimal age differences. McKee (2001) examined medical decision making and found that younger adults may be slightly more influenced by the frame than are older adults. However, this trend was not significant, and is inconsistent with what is suggested by research that examines age differences in cognitive processing. Inconsistencies in the literature on the effect of age and frame on decisions support the need for studies that examine the interactions between age and the manner in which information is framed. As suggested by the cognitive processing literature, perhaps older adults will be more likely to use heuristic processing than will younger adults. Thus, older adults may be more influenced by the framing of the treatment options than will younger adults. 
Age and cognitive ability. Another individual characteristic that is potentially important to examine is an individual's cognitive ability. Potential age variations in cognitive processing (i.e., analytical versus heuristic) have been explained by differences in cognitive capacity (Yates \& Patalano, 1999). That is, it is argued that older adults may use heuristic processing to a greater extent than do younger adults in order to compensate for age-related cognitive decline (Finucane et. al. 2002). It is assumed that older adults suffer from declines in fluid intelligence; therefore, decreasing their cognitive capacity, which may lead to a greater reliance on heuristics rather than analytical processing. Thus older adults may be more likely to be influenced by the frame of the treatment options. A measure of cognitive abilities that assesses fluid and crystallized intelligence separately is needed in order to test this claim. In addition, working memory has often been linked to cognitive ability (Engle, 2002); however, recent literature emphasizes the notion that working memory and intelligence are different constructs (Ackerman, Beier, \& Boyle, 2000). Therefore, a separate measure of working memory may also help to understand potential age differences in the susceptibility of frame.

Experience

Research suggests that experience influences decision making. Meyer, Russo, and Talbot (1995) found that previous knowledge about breast cancer and treatment for breast cancer affected whether women chose lumpectomy, mastectomy, or radiation therapy. Also, women mentioned experience with breast cancer when asked to provide a rationale for whether they made an immediate or delayed treatment decision. Zwahr (1994) examined the effect of previous knowledge on women's decisions about estrogen replacement therapy and found that previous knowledge influenced the number of treatments they felt would alleviate symptoms, and the number of times they compared various treatment options. In an examination of older 
adults' endorsement of interpersonal and individual health problem solving strategies, Snyder (2004) found that experience impacted the ratings of problem solving strategies when dealing with both heart and arthritis problems. Pierce (1993) suggests that when making medical decisions individuals remember their own and others experiences with the problems. Therefore, although few young adult women personally experience breast cancer, experience through another person (vicarious experience) may also impact decisions. Patrick and Strough (2004) found that personal and vicarious experience combined was related to the number of strategies generated for solving everyday problems dealing with relocation; adults with experience generated more strategies than those without experience. Together, this research suggests that both personal and vicarious experience (i.e., experience through another person) with breast cancer may impact the decision for treatment options.

\section{Cognitive Processing and Experience/Expertise}

Experience may also influence the type of cognitive processing (i.e., analytical versus heuristic) a persons uses to make decisions. Increased experience may lead to a greater reliance on heuristic processing. According to Fuzzy Trace Theory (Reyna \& Brainerd, 1995), which has been used to explain the framing effect, decision making involves both verbatim and gist mental representations; however people tend to rely on gist representations. In addition, "intuitive gistbased processing supplants analytical verbatim-based processing as people gain experience or novices become experts" (p. 66; Reyna, 2004). There is a large literature that examines decision making by experts in various domains, including gambling (Loke \& Tan, 1992), law (Johnson, Johnson \& Little, 1984), physics, (Chi, Feltovich \& Glaser, 1981), and medical decision making (Johnson, 1981). In a study that examined expert cardiologists and less expert physicians' decisions to admit a patient suffering from chest pains, results indicated that expert cardiologists 
relied more on heuristic processing than on analytical processing. Expert cardiologists used less information to make a decision than did the less expert physicians; expert cardiologists considered only whether a heart attack was imminent or not. If individuals with experience rely on heuristic processing, the frame of the option may influence choice. However, it can also be argued that experience with breast cancer may increase motivation, which is generally associated with analytical processing (Cacioppo \& Petty, 1982). If individuals with experience are more motivated than those without experience to engage in analytical processing, the frame of the option may not influence choice. Experience may influence motivation or the type of cognitive processing used which, in turn, could influence the susceptibility of framing effects. Therefore, experience may moderate the relationship between frame and decision.

\section{Sensation Seeking}

An individual's general risk-taking propensity may also impact decisions that involve risk. Sensation seeking can be defined as a personality trait that involves a person's desire for novel and intense sensory stimulation (Arnett, 1998; Zuckerman, 1994). Sensation seeking has been linked to various risky behaviors, including erratic driving, promiscuous sexual behavior, and drug abuse (see Zuckerman, 1994 for review). Arnett (1998) examined risky behavior in adults aged 20-28 years and found sensation seeking to be positively associated with risky driving, substance abuse, and risky sexual behavior. In addition, Rolison and Scherman (2002, 2003) found that sensation seeking was positively related to both adolescents' and young adults' risky behaviors respectively. Examination of age differences in risky behaviors is scarce and inconsistent (Yates \& Patalano, 1999). Although sensation seeking has consistently been shown to be related to various risky behaviors, the influence of sensation seeking on medical decisions has not been examined. It can be argued that an individual who is more likely to take risks in 
general may be more likely to choose the risk-seeking option regardless of the way in which it is framed. Conversely, an individual who is less likely to take risks may be more likely to choose the risk-averse option regardless of the way in which it is framed. Thus, the wording, or frame, of treatment options may not influence treatment decisions for women who score extremely high (risk takers) or extremely low (risk avoiders) on sensation seeking. Thus, sensation seeking may moderate the relation between frame and decision.

\section{Analytical Processing and Need for Cognition}

Given the information presented above on cognitive processing, the type of cognitive processing (analytical or heuristic) may impact the influence of frame. Therefore, another variable that needs to be examined is individual use of analytical versus heuristic processing. As suggested by Kahneman (2003), an individual who generally uses analytical processing may not be influenced by the frame whereas, an individual who generally relies upon heuristics when making decisions may be influenced by the frame. Thus cognitive processing type (analytical versus heuristic) may mediate the relationship between frame and decisions.

An individual's tendency, or need, to engage in effortful thinking (i.e., analytical processing) is referred to as an individual's need for cognition (Cacioppo \& Petty, 1982). Need for cognition has been shown to be negatively associated with susceptibility of framing effects (Chatterjee, Heath, Milberg, \& France, 2000; Simon, Fagley, \& Halleran, 2004; Smith \& Levin, 1998). Smith and Levin examined an individual's need for cognition and message frame on monetary tasks and medical decision making using a format consistent with the Asian disease design. Results of the study indicated that for both types of tasks, framing effects emerged only for participants low in need for cognition, or low in analytical processing. Similarly, Simon and colleagues found that the framing effect was more pronounced in individuals with a low need for 
cognition. Perhaps frame will influence treatment decision in women with a low need for cognition to a greater extent than it will for women high in need for cognition. Therefore, need for cognition may moderate the relationship between frame and decisions.

\section{Statement of the Problem}

The issue of women's health has increasingly gained the attention of physicians, researchers, and policy makers. Females comprise the majority of the U.S. population, and there are many more females than males in older adulthood (US Census, 2003). Breast cancer is a common form of cancer in women (ACS, 2005). Individual characteristics, such as age, and other variables in combination with how information is framed, may influence the decisions that women make when presented with treatment options about breast cancer. Understanding the decision-making process is very important for both medical service providers and women who may be faced with decisions about treatments for breast cancer. Research on medical decision making indicates that the way in which a treatment option is framed or worded in terms of either gains or losses influences peoples' decisions on treatment (McNeil et al., 1982; Rybash \& Roodin, 1989; Tversky \& Kahneman, 1979), that is, a framing effect appears. Although the framing effect in decision making has been reliably shown in many different areas, little research examines how frame in combination with age, influence medical decisions. In order to gain a better understanding of the process involved in medical decision making, new research must examine the various factors may impact choice of treatment. For example, do individual characteristics, such as cognitive ability, cognitive processing type (i.e., analytical versus heuristic), need for cognition, sensation seeking and experience with the problem mediate or moderate the effects of age and frame on medical decisions? The current study was designed to contribute to the literature by examining the individual and interactive effects of individual 
characteristics on women's susceptibility to the framing effect when presented with treatment decision vignettes about breast cancer.

Design

The main subject variables was age (younger adult or older adult), and the main independent variable was frame (treatment options presented either positively or negatively). Additional subject variables were cognitive ability, analytical processing versus heuristic processing, need for cognition, experience, and sensation seeking. Frame (positive and negative) was counterbalanced and presented as a within-subjects variable in 3 domains. The domains were breast cancer, general cancer, and non-cancer. The general cancer and non-cancer domains were presented to examine the generalizability of the findings. In the primary analyses, frame was analyzed as a between-subjects variable for the breast cancer domain only. The other subject variables (individual difference variables) were between-subjects variables. The dependent variable was treatment decision (i.e., the degree of likelihood of choosing a riskseeking versus risk-averse treatment option). The dependent variable was a continuous variable. Research Questions

1) How do age and framing of the message (positive or negative) affect women's choice of treatment options for breast cancer?

2) Does type of cognitive processing (i.e., analytical versus heuristic) mediate age differences in treatment decision?

3) Do individual characteristics such as cognitive ability, need for cognition, experience, and sensation seeking moderate the relationship between frame and treatment decision? 
Hypotheses

Research Question 1

\section{Frame}

1) The influence of message frame on health decision making has consistently been shown in the literature (Frisch, 1993; Reyna \& Brainerd, 1991). It was hypothesized that the frame, or way in which treatment options were worded, would impact treatment decision in the same way as that found in the classic framing study (Tversky \&Kahneman, 1979). When the treatment option was framed positively in terms of number of women cured, people would choose a more risk-averse option. When the treatment option was framed negatively in terms of number of women who would die, people would choose a more risk-seeking option.

Age x Frame

2) Research suggests that older adults may be more likely than younger adults to engage in heuristic processing (Park, 1999). Heuristic processing involves the use of mental shortcuts, which may make individuals more susceptible to the framing effect. Therefore, it was hypothesized that there would be a significant frame $\mathrm{x}$ age interaction; frame would have more of an effect on older women than on younger women.

\section{Research Question 2}

\section{Type of Cognitive Processing}

3) Research indicates that the type of cognitive processing (i.e., analytical versus heuristic) may be associated with susceptibility to framing effects (Kahneman, 2003). It was hypothesized that women who relied on heuristic processing would be influenced by the way in which a message is framed whereas women who relied on analytical processing 
would not be influenced by frame. Thus, preferred cognitive processing type (i.e., analytical versus heuristic) was expected to mediate the relationship between frame and decision.

\section{Research Question 3}

\section{Cognitive Ability}

4) Individuals with lower cognitive ability may be more likely to use heuristic processing; therefore, it was hypothesized that individuals with lower cognitive ability scores would be influenced more by the frame than would individuals who scored higher on cognitive ability. Thus, cognitive ability was expected to moderate the relationship between frame and decision.

\section{Experience}

5) Reyna (2004) suggests that heuristic processing overrides analytical processing as individuals gain experience. It was hypothesized that frame would influence women with experience with breast cancer more than women with no experience of breast cancer; thus, experience was expected to moderate the effect of frame on decision.

\section{Sensation Seeking}

6) Sensation seeking has been linked to various risky behaviors, including erratic driving, promiscuous sexual behavior, and drug abuse (see Zuckerman, 1994 for review).

Therefore, it was hypothesized that the wording, or frame, of treatment options would not influence treatment decisions for women who scored extremely high (risk takers) or extremely low (risk avoiders) on sensation seeking. Thus, sensation seeking was expected to moderate the effect of frame on decisions. 


\section{Need for Cognition}

7) Greater need for cognition has been shown to be negatively associated with susceptibility to the framing effect (Chatterjee, Heath, Milberg, \& France, 2000; Simon et al., 2004; Smith \& Levin, 1998). Therefore, it was hypothesized that frame would influence treatment decisions in women with a low need for cognition to a greater extent than it would for women high in need for cognition. Thus, need for cognition was expected to moderate the relationship between frame and decision.

\section{Participants}

Using the Sample Power statistical program, a power analysis for a $2 \times 2$ interaction showed that 132 women were needed to detect medium effect sizes $(>.25)$ with $81 \%$ power. A power analysis for a regression with two variables and an interaction yielded sufficient power (power $>.90$ ) to detect medium effect sizes $(>.25)$.

The sample consisted of sixty-eight young adult women ( $M$ age $=19.10$ years, $S D=$ 1.54) who were college students and sixty-six community-dwelling women aged sixty years and older $(M$ age $=70.76$ years, $S D=7.10)$. All of the younger women were single; for older women, $43.9 \%$ were married, $37.9 \%$ were widowed, $13.6 \%$ were divorced, $1.5 \%$ was never married, and 3\% were living as married. The sample was 94.8\% Caucasian. There were 2 African American older women, 4 Asian younger women, and 1 younger woman reported as other.

The college students were recruited from undergraduate psychology classes and recruitment flyers posted around the campus of West Virginia University. College students received extra credit in undergraduate psychology courses as a thank you for participation. The older adults were recruited from senior centers, community facilities, and residential institutions, 
and through personal contacts and recruitment flyers posted in the community. Participants were also recruited from the sample used for a National Institute of Health grant-funded study (R03; OMB No. 0925-0001; Collaborative Everyday Problem-Solving: Gain or Loss, J. Strough primary investigator). A total of $56.7 \%$ of the current sample participated in the grant-funded study prior to participating in the current study. Both younger women $(N=17 ; 39.7 \%)$ and older women $(N=49 ; 74.2 \%)$ were recruited from the grant-funded study. Immediately after the participants completed the grant-funded study they were invited to participate in the current study at that time, and if they agreed, they completed the current study. If they could not complete the current study at that time, they were asked if they would like to participate in future studies. Each person who agreed to be considered for a future study filled out an information sheet with their contact information. The time between participation in the grant-funded study and the current study varied from about 2 months for older women and 3 weeks for younger women. Older adult participants were given $\$ 20.00$ each as a "thank you" for participation in the grant-funded study. Younger adult participants were given the choice of extra credit or $\$ 20.00$ each as a "thank you" for participation in the grant-funded study. With the exception of income, women who participated in the grant-funded study were not significantly different from women who did not participate in the grant-funded study (see Table 2 and Table 3 ). In addition, the women who did participate in the grant-funded study $(M=3.74, S D=.21)$ did not make significantly different treatment decisions than did women who did not participate $(M=3.50, \mathrm{SD}$ $=.24)$ in the grant-funded study, $F(1,133)=.54, p=.46$.

\section{Measures}

Cancer treatment decision vignettes were used to manipulate the message frame. Vignettes have been shown to be a useful way to examine decision making (Tversky \& 
Kahneman, 1981). Participants were presented with three hypothetical situations: 91) breast cancer, (2) general cancer and (3) non-cancer. A complete copy of the measures can be found in Appendix A.

Breast Cancer Vignette

The breast cancer vignette was adapted from Tversky and Kaheman (1979) and presented as follows:

You have been diagnosed with a rare form breast cancer. Otherwise, you are in an excellent state of health. It is expected that 600 women will be diagnosed with this type of breast cancer this year. There are two experimental treatment programs that involve equal amounts of both drug therapy and radiation. Your physician describes the calculated odds of being cured for each treatment program. Please rate the likelihood of choosing a treatment option (see treatment options below).

\section{General Cancer Vignette}

Participants were presented with a general (i.e., non-breast cancer specific) vignette to determine generalizability of results. The vignette was taken from Fagley and Miller (1987). The National Institute for Cancer has two possible treatments for cancer, which could become standard treatments across the country. There are adequate resources to implement only 1 program (see options below).

\section{Non-cancer Vignette}

Participants were presented with a non-cancer vignette to determine generalizability of results. The vignette was taken from Simon, Fagley, and Halleran (2004). 
A ship hits a sunken barge and is sinking in the middle of the ocean. There are 600 people on the ship. Their lives are in danger. Two options are proposed. Assume that the exact estimates of the consequences of the options are as follows: (see options below).

Frame

The options for the each of the vignettes were framed either positively or negatively. The wording of the options was based on the classic framing study by Tversky and Kahneman (1979). Outcomes for the positively and negatively framed treatment programs were objectively equivalent and would have equal expected outcomes. Although Tversky and Kahneman (1979) scored their problems as categorical (i.e., risk taking or risk averse), a continuous measure of the likelihood of choosing a more or less risky treatment was used in this study. Therefore, participants were asked to rate on a 7-point Likert-type scale modified from Levin, Gaeth, Schreiber, and Lauriola (2002) the likelihood of choosing each option. The scale ranged from 1 $=$ Definitely Would Choose Treatment Option A to $7=$ Definitely Would Choose Treatment Option B. Higher numbers indicated greater preference for risky options. Levin and colleagues found a significant mean difference score of $1.09(\mathrm{p}<.001)$ for positive and negative framed treatment programs.

Breast cancer vignette. For the breast cancer vignette, the positive and negative frames were as follows:

\section{Positive Frame}

A) In treatment program A, 200 women will be cured. (risk averse)

B) In treatment program $B$, there is a $1 / 3$ chance that 600 women will be cured and a $2 / 3$ chance that no women will be cured. (risk seeking) 


\section{Negative Frame}

A) In treatment program A, 400 women will die. (risk averse)

B) In treatment program $B$, there is a $1 / 3$ chance that no women will die, and a $2 / 3$ chance that 600 women will die. (risk seeking)

General cancer vignette. For the general cancer vignette, the positive and negative frames were as follows:

\section{Positive Frame}

A) If treatment $A$ is adopted, of every 600 people who get cancer 200 will be saved (risk averse).

B) If treatment $B$ is adopted, there is a $1 / 3$ chance that 600 people will be saved and a $2 / 3$ chance that no people will be saved (risk seeking).

\section{Negative Frame}

A) If treatment $\mathrm{A}$ is adopted, of every 600 people who get cancer 400 will die (risk averse).

B) If treatment $B$ is adopted, there is a $1 / 3$ chance that no people will die and a $2 / 3$ chance that 600 people will die (risk seeking)

Non-cancer vignette. For the non-cancer vignette, the positive and negative frames were as follows:

\section{Positive Frame}

A) If option A is adopted, 200 people will be saved (risk averse).

B) If option B is adopted, there is a $1 / 3$ chance that 600 people will be saved and a $2 / 3$ chance that none will be saved (risk seeking). 


\section{Negative Frame}

A) In option A, 400 people will die (risk averse).

B) In option $B$, there is a $1 / 3$ chance that no people will die, and a $2 / 3$ chance that 600 people will die (risk seeking)

\section{Sensation Seeking}

According to Zuckerman (1994), sensation-seeking is a strong predictor of risky behavior. The Impulsive Sensation Seeking Scale (ImpSS, Zuckerman) is used as a way to measure general risk-taking behavior. Although the ImpSS has not been validated on older adults, currently the field lacks a better scale to access risk-taking propensity. Participants were asked to state true or false as to whether they believe that each of 19 statements described them (e.g., "I like doing things just for the thrill of it", "I often do things in impulse"). Zuckerman reported Cronbach's alphas that range from .77 to .82 . The ImpSS scale correlated highly with Zuckerman's longer Sensation Seeking Scale (SSS, $r=.66$ ). Participants received 1 point for each "true" response, except for item 6, in which a "false" response received 1 point. Higher scores indicated higher sensation seeking. Cronbach's alpha for the current sample was .78. The scale had a possible range from 0 to 19; younger women had an actual range of 0 to 17 ( $M=$ $9.59, S D=4.04)$; older women had an actual range of 0 to $17(M=5.53, S D=4.17$; see Table 4).

\section{Cognitive Ability}

Crystallized and fluid intelligence. Intelligence was assessed using the original Kauffman Brief Intelligence Test (K-BIT, Kaufman \& Kaufman, 1990). The K-BIT yields an overall intelligence score and separate measures of crystallized and fluid intelligence. There are three sections: expressive vocabulary, definitions, and matrices. The expressive 
vocabulary section consists of pictures that the participant is asked to name (e.g., fire hydrant). The definitions section consists of clues and words with letters missing. The participant is asked to fill in the missing letters and spell the word (e.g., Santa's entrance = chimney). The definitions section is timed; 30 seconds is allowed for each questions. The matrices section consists of pictures and relationships between pictures. Participants are asked which of the given options goes best with the given pictures or fits the blank (e.g., a truck goes with other vehicles). The measure is an adequate substitution for the more commonly used WAIS (correlations between the two measures range from .52 to .75, Kaufman \& Kaufman). Test administrators were trained according to the instructions in the K-BIT manual. Each research assistant must have correctly completed 3 practice sessions in order to administer the test. The test took approximately 20 minutes for the younger women to complete and 45 minutes for the older women to complete.

Crystallized intelligence. Crystallized intelligence scores were calculated, according to the K-BIT manual, by summing the raw scores for the expressive vocabulary and definitions sections and then translating the sum to a standardized score. Raw scores were calculated by subtracting the numbers of errors from the highest item administered. For the crystallized intelligence score, younger women's scores ranged from 84 to 128 ( $M$ $=100.81, S D=9.44)$; older women's scores ranged from 75 to $130(M=105.18, S D=$ 12.93; see Table 4).

Fluid intelligence. Fluid intelligence scores were calculated, according to the KBIT manual, by translating the raw score for the matrices section into a standardized score. Raw scores were calculated by subtracting the numbers of errors from the highest item administered. For the fluid intelligence score, younger women's scores ranged from 48 to 
$128(M=103.38, S D=11.98)$; older women's scores ranged from 44 to $126(M=102.91$, $S D=15.97$; see Table 4).

Composite score. A composite score was calculated, according to the K-BIT manual, by summing the standardized scores for crystallized and fluid intelligence. The sum was then translated into a standardized composite score. For the composite score, younger women's scores ranged from 67 to $124(M=102.23, S D=9.05)$; older women's scores ranged from 61 to $132(M=104.15, S D=13.96$; see Table 4 for total sample means).

Working memory. Forward and backward digit span tasks from the WAIS-R-III (Weschler, 1997) were used to access working memory. For the forward digit span task, participants were asked to repeat a sequence of numbers in the same order as the administrator stated them. For the backward digit span task, participants were asked to repeat a sequence of numbers in the opposite order in which the administrator presented them. For participants from the NIH funded study, there was approximately 2 months between assessment of working memory and completion of the decision-making tasks for some of the participants. Therefore, data on working memory was collected but not analyzed because this aspect of cognitive functioning is variable.

Experience. Experience has been shown to influence various aspects of the medical decision-making process (Meyer, Russo, \& Talbot, 1995; Snyder, 2004; Zwahr, 1999). To assess personal experience, the participants were asked to indicate whether they had ever been diagnosed with breast cancer (yes/no), the month and year of diagnosis, type of treatment received, and whether the cancer was cured or is in remission. To assess vicarious experience, the participants were asked if they had a close friend or relative who had been diagnosed with 
breast cancer (yes/no), the relationship of the person diagnosed (e.g., relative or friend), how close they feel to that person, and the extent to which they were involved in that person's medical decisions. Total experience was considered when the participant stated "yes" to at least one of the personal or vicarious experience problems. Younger and older women did not significantly differ on total experience or vicarious experience reported (see Table 5). No younger women reported personal experience with breast cancer.

Self-rated health. The 4-item self-rated health scale from the Multilevel Assessment Instrument (Lawton, Moss, Fulcomer \& Kleban, 1982) was used to assess perceived health and was used as background information. Participants were asked to rate their overall health at the present time from (1) Excellent to (4) Poor. Participants were asked "Is your health now (1) Better, (2) About the Same, or (3) Not as Good as it was 3 Years Ago?" Participants were asked if their health problems stand in the way (1) Not at All, (2) A Little or (3) A Great Deal of doing the things they want to do. Participants were asked "Compared with most other people your age, would you say your health is: (1) Better, (2) The Same or (3) Not as Good. Raw scores were reversed so that higher scores indicated better-perceived health. A total perceived health score was computed by summing the scores across each item. Cronbach's alpha for the scale in the current sample was .76. The scale had a possible range from 4 to 16 ; younger women had an actual range of 7 to $13(M=10.44, S D=1.54)$; older women had an actual range of 4 to $13(M=$ 9.25, $S D=2.12 ;$ see Table 4).

Type of cognitive processing and need for cognition. The 31-item Rational-Experiential Inventory (REI; Epstein, Pacini, Denes-Raj, \& Heier, 1996) was used to assess cognitive processing (i.e., analytical versus heuristic processing). The REI consists of two unipolar subscales: a 19-item modified Need for Cognition scale (NFC, Cacioppo \& Petty, 1982) that 
examines analytical processing and a new 12-item Faith in Intuition (FI) scale developed to examine heuristic processing. Participants were asked to rate on a 5 point Likert-type scale from (1) Completely False to (5) Completely True the degree to which each statement described them. Epstein and colleagues reported that both subscales were sufficiently reliable: $\mathrm{NFC}$ alpha $=.77$; FI alpha $=.80$.

To calculate need for cognition and faith in intuition scores, the average of the items within each subscale was computed. To compute the need for cognition score, scale items 1, 2, $4,5,6,7,9,10,11,13,15,16$, and 18 were reverse scored so that higher scores indicated a higher need for cognition. No items needed to be reverse scored to compute the faith in intuition score. Higher scores indicated a higher faith in intuition. To address the dual process conceptualization of cognitive processing, need for cognition and faith in intuition were analyzed as separate subscales.

To address the notion that cognitive processing may be a unitary process, a total cognitive processing score was also computed by averaging all of the items. Items 1, 2, 4, 5, 6, $7,9,10,11,13,15,16,18$ of the need for cognition scale, and all of the items on the faith in intuition scale (i.e., numbers 19-30) were reversed scored. Higher scores indicated higher analytical processing.

In the current sample the need for cognition subscale had a Cronbach's alpha of .77; the faith in intuition subscale had a Cronbach's alpha of .80; and the total scale had a Cronbach's alpha of .76. Attempts to improve the reliability of the scale by dropping items failed. The total cognitive processing (analytical and heuristic combined) scale had a possible range from 0 to 5; younger women had an actual range of 1.74 to $3.90(M=2.95, S D=.40)$; older women had an actual range of 2.00 to $3.83(M=2.91, S D=.47)$. The need for cognition scale had a possible 
range from 0 to 5; younger women had an actual range of 1.58 to $4.37(M=3.27, S D=.52)$; older women had an actual range of 1.79 to $4.68(M=3.21, S D=.70)$. The faith in intuition scale had a possible range from 0 to 5; younger women had an actual range of 1.75 to 4.67 ( $M=$ $3.57, S D=.54)$; older women had an actual range of 2.42 to $4.92(M=3.56, S D=.52$; see Table 4 for descriptive information on older and younger women and total sample). Analyses were conducted with the two subscales (need for cognition and faith in intuition) and the total cognitive processing score.

Demographics information. A demographic questionnaire contained general questions regarding sex, age, race, education, residency, income, marital status (i.e., married, living as married, widowed, divorced, never married), living status (i.e., alone, with others), work history, current employment and statistics courses taken (for younger women only). As background health information, participants were asked to provide information regarding the gender of physician, frequency of doctor visits, access to health care and general health conditions. As background information, knowledge about breast cancer was assessed using Vaeth's (1993) 16item scale. Participants were asked to state whether information concerning the risk factors and demographic information about breast cancer was True or False. Participants received 1 point for each correct answer (i.e., "true" response to true statement, "false" response to false statement). The scale had a possible range from 0 to 16; younger women had an actual range of 8 to $15(M=11.43, S D=1.70)$; older women had actual range of 7 to $15(M=11.11, S D=1.87$; see Table 4).

\section{Procedure}

The study consisted of 1 session. The sessions took place either in 1) the Life-Span Developmental Research Laboratory in the Life Sciences Building at West Virginia 
University, 2) various community senior centers, 3) residential living communities, and 4) older women's homes. Participants completed the study alone in a quiet, private area. The study was described to the participants by the first author or a member of the research team which consisted of undergraduate and graduate research assistants. Informed consent and HIPAA authorization was obtained. The forward and backward digit span tasks were completed first. The task took about 10 minutes for younger adults and 5 minutes for older adults. The K-BIT was administered next. The test took approximately 20 minutes for the younger women to complete and 45 minutes for the older women to complete. Then participants were asked to complete the Decision Making Questionnaire, which consisted of the remainder of the self-report questionnaires. Directions on how to complete the questionnaires were thoroughly described and any questions were answered via verbal explanation to the participant. The order of the questionnaires was follows: vignettes, demographic information, the REI, the ImpSS, and the Knowledge Scale. The entire session took approximately 1 hour for younger women and 1.5 hours for older women. The breast cancer vignette was presented first to all participants and was counterbalanced (i.e., half of the women received the positively framed vignette first and the other half received the negatively framed vignette first). The general cancer and non-cancer vignettes were then presented and were also counterbalanced for a total of 16 versions. The general cancer and non-cancer vignette were used to examine generalizability, or whether women's decisions were specific to the breast cancer domain or were due to the wording of options regardless of domain. In the primary analyses, frame was analyzed as a between-subjects variable. The first vignette that each woman received served as the frame, either positive or negative, and the women's continuous score of the treatment option for that vignette served 
as the dependent variable in the analyses of the effect of frame on breast cancer treatment decisions. Higher scores indicated riskier options.

Results

Before conducting analyses, missing data for the treatment decision ratings for each of the vignettes was replaced using the overall mean within each domain and frame. For the positively framed breast cancer vignette, $5 \%$ of the data was replaced ( 2 of younger women, 5 of older women). For the negatively framed breast cancer vignette, $4 \%$ of the data replaced ( 3 of younger women, 2 of older women). For the positively framed general cancer vignette, $4 \%$ of the data was replaced ( 2 of younger women, 4 of older women). For the negatively framed general cancer vignette, $5 \%$ of the data was replaced ( 1 of younger women, 6 of older women). For the positively framed non-cancer vignette, $6 \%$ of the data was replaced ( 3 of younger women, 5 of older women). For the negatively framed non-cancer vignette, $3 \%$ of the data was replaced ( 2 of younger women, 2 of older women). There was no distinguishable pattern to the missing data ${ }^{1}$.

Boxplots were used to screen for outliers separately for each vignette (breast cancer positively framed, breast cancer negatively framed, general cancer positively framed, general cancer negatively framed, non-cancer positively framed, non-cancer negatively framed). Results indicated that no significant outliers were present. Skewness and kurtosis were used to examine normality of the data. Although skewness and kurtosis values indicated a deviation from normality (i.e., did not equal zero), the sample size was large enough that deviation from normality would not make a substantive difference in analyses (Tabachnick \& Fidell, 2001).

\footnotetext{
${ }^{1}$ Results of analyses conducted without missing data imputed were not significantly different than those reported here. These data are available upon request.
} 


\section{Descriptive Statistics}

Descriptive statistics for age, education, race, marital status, experience, knowledge about breast cancer, self-rated health, cognitive processing, need for cognition, faith in intuition, sensation seeking, intelligence (total), crystallized intelligence, fluid intelligence, and income were examined for both the younger and older adult age groups (see Table 4 and Table 5). The Influence of Age and Frame on Treatment decision

To address research question 1, (How do age and framing of the message (positive or negative) affect women's choice of treatment options for breast cancer?) a hierarchical regression was conducted to examine the affect of age and frame on treatment decision. Frame was dummy coded; positive frame $=1$, and negative frame $=0$. Age and frame were predictor variables and were entered in the first step of the regression. The interaction of age $\mathrm{x}$ frame was computed, centered, and entered in the second step of the regression. Treatment decision was the criterion. Treatment decision was a continuous variable. Age was entered as a continuous variable in the regression. Results indicated that age and frame accounted for a significant amount of treatment decision variability, $R^{2}=.14, F(2,133)=10.92, p<.001$. Age was not a predictor of treatment decision, $t(133)=1.21, p=.23$. Frame significantly predicted treatment decision, $t(133)=-4.52, p<.001$. As predicted, women presented with the negative frame endorsed riskier treatment decisions. The model that included the age $\mathrm{x}$ frame interaction accounted for a significant account of the treatment decision variance, $R^{2}=.23, F(3,133)=$ 12.93, $p<.001$. The age $\mathrm{x}$ frame interaction term accounted for a significant portion of the variance in treatment decision, $t(133)=-3.83, p<.00$ (see Table 6). 
The Age x Frame Interaction

In order to localize the age $\mathrm{x}$ frame effect found in the analysis for research question 1 , a 2 (age group) x 2 (frame) ANOVA was conducted. Older (i.e., over the age of 60 years) and younger (i.e., between the ages of 18-29 years) were recruited in order to examine age differences. Thus, age was entered as a between-subjects categorical subject variable, frame was a between-subjects independent variable, and the continuous rating of treatment decision was the dependent variable. Results showed a significant main effect of frame, $F(1,133)=23.07, p<$ .01 , partial $\eta^{2}=.15$, and a significant age $\mathrm{x}$ frame interaction, $F(1,133)=14.98, p<.01$, partial $\eta^{2}=.10$. Follow-up ANOVAs showed that older women presented with the negative frame $(M=$ 5.06, $S D=1.81$ ) indicated a greater likelihood of choosing a risk-seeking treatment option than did older women presented with the positive frame $(M=2.62, S D=1.94)$. For younger women, there were no significant differences in ratings for the negatively $(M=3.60, S D=1.00)$ or positively $(M=3.34, S D=1.61)$ framed treatment options (see Figure 3$)$. Thus, the hypothesis that there would be an age x frame effect was supported. Frame influenced older women's decisions but did not influence in younger women's decisions.

Cognitive Processing as a Mediator

To address research question 2, (Does type of cognitive processing mediate age differences in treatment decision?) cognitive processing was examined using a mediation and a mediation moderation model. According to Holmbeck (1997), structural equation modeling may be the best strategy to examine mediators and moderators due to control of error; however, the current sample size $(N=134)$ was too small to use the technique. In the current study, Baron and Kenny's (1986) criteria for establishing a mediated moderation model were used. The criteria are 
follows: first, age and frame must both have a significant effect on treatment decision (determined in analysis for research question 1 above; see Paths $a_{1}$ and $a_{2}$ in Figure 4). Second, for type of cognitive processing to mediate the relationship between age and treatment decision, age must affect type of cognitive processing (see Path $b_{1}$ in Figure 4) and type of cognitive processing must affect treatment decision (Path $b_{2}$ in Figure 4). Two hierarchical regression analyses would test these requirements: (1) age, frame, and age x frame (centered and entered into separate step of the regression) as predictors and type of cognitive processing as the criterion variable; and (2) age, frame, and age $\mathrm{x}$ frame (centered and entered into separate step of the regression) as the predictors and treatment decision as the criterion variable. To demonstrate complete mediation, age would not affect treatment decision when type of processing was controlled (see Path $a_{l}$ in Figure 4). Mediated moderation would be indicated if age $\mathrm{x}$ frame affected treatment decision (see Path $c_{2}$ in Figure 4), and age $\mathrm{x}$ frame affected type of cognitive processing (see Path $c_{1}$ in figure 4), and type of cognitive processing affecting age (see Path $b_{1}$ in Figure 4). The final step in the criteria is tested via a regression with age, frame, type of cognitive processing, age $\mathrm{x}$ frame, and type of cognitive processing $\mathrm{x}$ frame (each interaction centered and entered in separate steps of the regression) as the predictors and treatment decision as the criterion variable. For cognitive processing to moderate the relationship between age and frame, the effect of age $\mathrm{x}$ frame on treatment decision must be reduced from the previous regressions (1) and (2) above (as indicated by a decrease in the $\beta$ weights).

The hierarchical regression conducted to answer research question 1 indicated that age did not significantly affect treatment decision, $t(133)=1.21, p=.23$; therefore, Baron and Kenny's (1986) criteria for establishing a mediation, or mediated moderation model were not met. Thus, the hypothesis that cognitive processing would mediate the age $\mathrm{x}$ frame effect was not 
supported because there was no main effect of age on treatment decision. Cognitive processing was examined as a predictor in the exploratory analyses described in the exploratory analyses section.

\section{Individual Characteristics as Moderator Variables}

To address research question 3 , individual difference characteristics were tested as moderator variables. In order to establish that individual characteristic variables moderate the relationship between frame and treatment decision, Baron and Kenny’s (1986) criteria for establishing moderation must be met. First, frame must be related to treatment decision (determined in analysis for research question 1; see Path $a$ in Figure 2). Second, the moderator variable (individual characteristic) must be related to treatment decision (see Path $b$ in Figure 2). Finally, the moderator variable $\mathrm{x}$ frame interaction must be significant in order to demonstrate a moderator effect (see Path $c$ in Figure 2). The first step was established in the analysis for research question 1; frame did significantly predict treatment decision, $t(133)=-4.52, p<.00$ (i.e., Path $a$ in Figure 2 was significant). The second step in the moderator model was that each moderator variable was a significant predictor of treatment decision. Analyses for each potential moderator variable are described below.

\section{Cognitive Ability}

To establish that cognitive ability moderated the effect of frame on treatment decision, 1) frame must affect treatment decision (see Path $a$ in Figure 2), 2) cognitive ability must affect treatment decision (see Path $b$ in Figure 2), and 3) the frame $\mathrm{x}$ cognitive ability interaction must affect treatment decision (see Path $c$ in Figure 2). As noted above, step 1 was established in the analysis for research question 1; frame did significantly predict treatment decision, $t(133)=$ 4.52, $p<.00$ (i.e., Path $c$ in Figure 2 was significant). Analyses were conducted to test each 
index of cognitive ability (i.e., K-BIT composite as a measure of intelligence, K-BIT vocabulary as a measure of crystallized intelligence, K-BIT vocabulary as a measure of fluid intelligence) as a potential moderator.

Intelligence. A linear regression was conducted to examine the effect of intelligence, as assessed by the composite K-BIT score, on treatment decision. Intelligence was the predictor and treatment decision was the criterion. Treatment decision was a continuous variable.

Intelligence did not significantly predict treatment decision, $R^{2}=.01, F(1,133)=1.13, p=.29$ (Path $b$ in Figure 2 was not significant). Baron and Kenny's criteria for a moderator effect was not met; therefore, intelligence did not moderate the relationship between frame and treatment decision (see Table 7).

Crystallized intelligence. A linear regression was conducted to examine the effect of crystallized intelligence on treatment decision. Crystallized intelligence was the predictor and treatment decision was the criterion. Treatment decision was a continuous variable. Crystallized intelligence did not significantly predict treatment decision, $R^{2}=.17, F(1,133)=3.84, p=.06$ (Path $b$ in Figure 2 was not significant). Baron and Kenny's criteria for a moderator effect was not met; therefore, crystallized intelligence did not moderate the relationship between frame and treatment decision (see Table 7).

Fluid intelligence. A linear regression was conducted to examine the effect of fluid intelligence on treatment decision. Fluid intelligence was the predictor and treatment decision was the criterion. Treatment decision was a continuous variable. Fluid intelligence did not significantly predict treatment decision, $R^{2}=.06, F(1,133)=.46, p=.50$ (Path $b$ in Figure 2 was not significant). Baron and Kenny’s criteria for a moderator effect was not met; therefore, 
fluid intelligence did not moderate the relationship between frame and treatment decision (see Table 7).

Experience

To establish that experience moderated the effect of frame on treatment decision, 1) frame must affect treatment decision (see Path $a$ in Figure 2), 2) experience must affect treatment decision (see Path $b$ in Figure 2), and 3) the frame x experience interaction must affect treatment decision (see Path $c$ in Figure 2). As noted earlier, step 1 was established in the analysis for research question 1; frame did significantly predict treatment decision, $t(133)=-4.52, p<.00$ (i.e., Path $a$ in Figure 2 was significant). A linear regression was conducted to examine the effect of experience on treatment decision. Experience was the predictor and treatment decision was the criterion. Treatment decision was a continuous variable. Experience did not significantly predict treatment decision, $R^{2}=.00, F(1,133)=.15, p=.29$ (Path $b$ in Figure 2 was not significant). Baron and Kenny's criteria for a moderator effect was not met; therefore, experience did not moderate the relationship between frame and treatment decision (see Table 7). Thus, the hypothesis that experience would moderate the relationship between frame and decision was not supported.

Sensation Seeking

To establish that sensation seeking moderated the effect of frame on treatment decision, 1) frame must affect treatment decision (see Path $a$ in Figure 2), 2) sensation seeking must affect treatment decision (see Path $b$ in Figure 2), and 3) the frame x sensation seeking interaction must affect treatment decision (see Path $c$ in Figure 2). As noted earlier, step 1 was established in the analysis for research question 1; frame did significantly predict treatment decision, $t(133)=$ 4.52, $p<.001$ (i.e., Path $a$ in Figure 2 was significant). A linear regression was conducted to 
examine the effect of sensation seeking on treatment decision. Sensation seeking was the predictor and treatment decision was the criterion. Treatment decision was a continuous variable. Sensation seeking did not significantly predict treatment decision, $R^{2}=.09, F(1,133)$ $=1.14, p=.29$ (Path $b$ in Figure 2 was not significant). Baron and Kenny's criteria for a moderator effect was not met; therefore, sensation seeking did not moderate the relationship between frame and treatment decision (see Table 7). The hypothesis that sensation seeking would moderate the relationship of frame and decision was not supported. Need for Cognition.

To establish that need for cognition moderated the effect of frame on treatment decision, 1) frame must affect treatment decision (see Path $a$ in Figure 2), 2) need for cognition must affect treatment decision (see Path $b$ in Figure 2), and 3) the frame $\mathrm{x}$ need for cognition interaction must affect treatment decision (see Path $c$ in Figure 2). As noted earlier, step 1 was established in the analysis for research question 1; frame did significantly predict treatment decision, $t$ (133) $=-4.52, p<.001$ (i.e., Path $a$ in Figure 2 was significant). A linear regression was conducted to examine the effect of need for cognition on treatment decision. Need for cognition was the predictor and treatment decision was the criterion. Treatment decision was a continuous variable. Need for cognition $(\beta=-.18), t(133)=-2.13, p<.05$, significantly predicted treatment decision, $R^{2}=.03, F(1,133)=4.47, p<.05$ (i.e., Path $\mathrm{b}$ in Figure 2 was significant). Women who scored lower on the need for cognition scale endorsed riskier decisions than women who scored higher on the need for cognition scale.

In order to establish that need for cognition moderated the effect of frame on treatment decision, the frame $\mathrm{x}$ need for cognition interaction must also significantly affect treatment decision. A hierarchical regression was conducted to examine the effect of frame and need for 
cognition on treatment decision. Frame and need for cognition were predictor variables and were entered in the first step of the regression. The interaction of frame $\mathrm{x}$ need for cognition was computed, centered and entered in the second step of the regression. Treatment decision was the criterion. Treatment decision was a continuous variable. The regression model that contained frame, need for cognition, and the frame $\mathrm{x}$ need for cognition interaction was significant, $R^{2}=$ $.16, F(2,133)=12.11, p<.001$. However, analysis of the beta weights indicated that frame was the only significant predictor variable, $t(133)=-4.37, p<.001$. The frame $\mathrm{x}$ need for cognition interaction was not a significant predictor of treatment decision (Path $c$ in Figure 2 was not significant). Baron and Kenny's criteria for a moderator effect was not met; therefore, need for cognition did not moderate the relationship between frame and treatment decision (see Table 8). Thus, the hypothesis that need for cognition would moderate the relationship of frame and decision was not supported.

Exploratory Analyses

Generalizability. In order to examine whether the frame effect found in the analysis conducted to address research question 1 was specific to the breast cancer domain, a 3 (domain) x 2(frame) x 2(age group) repeated measures MANOVA was conducted. Results indicated significant main effects of domain, $F(2,131)=5.19, p<.05$, partial $\eta^{2}=.07$, and frame, $F(2$, $131)=5.19, p<.05$, partial $\eta^{2}=.07$. There were significant two-way interactions for frame $\mathrm{x}$ age group, $F(1,132)=25.31, p<.00$, partial $\eta^{2}=.16$, and domain $\mathrm{x}$ frame, $F(2,132)=6.23, p$ $<.05$, partial $\eta^{2}=.09$. The three-way interaction of domain $\mathrm{x}$ frame $\mathrm{x}$ age group was also significant, $F(2,131)=4.65, p<.05$, partial $\eta^{2}=.07$.

To localize the effect and examine the question of generalizability, a 3 (domain) x 2 (frame) repeated measures MANOVA was conducted for each age group. For younger women, 
there was a significant main effect for domain, $F(2,66)=3.49, p<.05$, partial $\eta^{2}=.16$. Simple contrasts that compared the general cancer and non-cancer domains to the breast cancer domain were conducted to follow up the significant main effect. Results showed a significant difference between the non-cancer and breast cancer domains, $F(1,67)=6.83, p<.01$, partial $\eta^{2}=.09$. Young women made riskier decisions in the non-cancer domain as compared to the breast cancer domain (see Table 9). There was no main effect of frame or a domain $\mathrm{x}$ frame interaction for the young women in this sample.

For older women, a 3 (domain) x 2 (frame) repeated measures MANOVA was conducted for older women. Results indicated a significant two-way interaction of domain and frame, $F$ (2, $64)=8.97, p<.00, \eta^{2}=.02$. Paired sample t-tests that compared the positive and negative frames in each domain were used to follow up the significant two-way interaction in order to examine the generalizability of the results. Results indicated a significant difference in older women's decisions in the positive frame as compared to the negative frame in all three domains: breast cancer domain, $t(65)=-2.13, p<.05$, general cancer domain, $t(65)=-5.51, p<.001$, and non-cancer domain, $t(65)=-3.21, p<.05$ (see Table 9 and Figure 5). That is, for older women, frame affected decisions in all three domains (breast cancer, general cancer, and non-cancer). Older women made riskier decisions when presented with the negative frame, regardless of domain. Domain did make a difference in younger adults' decisions; however, frame did not. Thus, results of the current study can not be explained as specific to the breast cancer domain. To localize the domain $\mathrm{x}$ frame interaction for older women, paired sample t-tests were conducted for each domain combination in each frame. In the positive frame, older women's decisions in the general cancer domain $(M=3.20, S D=2.02)$ were significantly different from decisions in the breast cancer domain $(M=2.81, S D=1.94), t(66)=-1.54, p=.13$. In the 
positive frame, older women's decisions in the non-cancer domain $(M=3.77, S D=2.10)$ were significantly different than decisions in the breast cancer, $t(66)=-4.22, p<.00$, and general cancer, $t(66)=-2.34, p<.05$, domains. In the positive frame, older women made significantly riskier decisions in the non-cancer domain as compared to both the breast cancer and general cancer domains. There were no significant domain differences in older women's decisions in the negative frame.

Self-rated health. In order to examine the effect of self-rated health on treatment decision, a linear regression was conducted. Self-rated health was the predictor variable and treatment decision was the criterion. Treatment decision was a continuous variable. Results indicated that self-rated health $(\beta=-.02)$ did not account for a significant amount of treatment decision variability, $R^{2}=.02, F(1,133)=.037, p=.85$ (see Table 4 for descriptive information on selfrated health).

Comfort speaking to physician. Participants were asked to rate on a Likert-type scale from 1 (Not At All Comfortable) to 5 (Very Comfortable) how comfortable they were speaking to their physician about their health. In order to examine the effect of level of comfort speaking to physician on treatment decision, a linear regression was conducted. Level of comfort speaking to physician was the predictor variable and treatment decision was the criterion. Treatment decision was a continuous variable. Results indicated that level of comfort speaking to physician $(\beta=.08)$ did not account for a significant amount of treatment decision variability, $R^{2}=.01, F(1$, $133)=.95, p=.33$.

Comfort asking for second opinion. Participants were asked to rate on a Likert-type scale from 1 (Not At All Comfortable) to 5 (Very Comfortable) how comfortable they were asking for a second opinion. In order to examine the effect of comfort asking for a second opinion on 
treatment decision, a linear regression was conducted. Comfort asking for a second opinion was the predictor variable and treatment decision was the criterion. Treatment decision was a continuous variable. Results indicated that comfort asking for a second opinion $(\beta=.04)$ did not account for a significant amount of treatment decision variability, $R^{2}=.04, F(1,133)=.24, p=$ .63 .

Cognitive processing and treatment decision. Although Baron and Kenny's (1986) criteria for establishing cognitive processing as a mediator or moderator of the age $\mathrm{x}$ frame interaction were not met, as an exploratory analysis, a linear regression was conducted to examine the effect of cognitive processing on treatment decision. Cognitive processing was the predictor and treatment decision was the criterion. Treatment decision was a continuous variable. Results indicated that the overall measure of cognitive processing (i.e., analytical and heuristic processing combined) was not related to treatment decision, $R^{2}=.16, F(1,131)=3.61, p=.06$ (see Table 10). When cognitive processing was examined as a dual process, heuristic processing (i.e., faith in intuition) was not related to treatment decision, $R^{2}=.02, F(1,131)=.04, p=.85$ (see Table 10). However, analytical processing (i.e., need for cognition) was significantly related to treatment decision, $R^{2}=.18, F(1,131)=4.45, p<.05$. Women with lower need for cognition made riskier decisions than did women high greater need for cognition (see Table 10).

The influence of age and frame on cognitive processing. A hierarchical regression was conducted to examine the effect of age, frame, and age $\mathrm{x}$ frame on cognitive processing (Paths $b_{1}, a_{1}$, and $c_{2}$ in Figure 4) in an attempt to better understand the age $\mathrm{x}$ frame interaction. Age and frame were predictor variables and were entered in the first step of the regression. Frame was dummy coded; positive frame $=1$ and negative frame $=0$. The interaction of age $\mathrm{x}$ frame was computed, centered and entered in the second step of the regression. Total cognitive processing 
score (i.e., analytical and heuristic processing combined) was the criterion. Age was entered as a continuous variable. Results indicated that age and frame did not account for a significant amount of the variance in total cognitive processing, $R^{2}=.02, F(2,133)=1.30, p=.28\left(\right.$ Paths $b_{1}$ and $a_{l}$ in Figure 4 were not significant). In addition, the age $\mathrm{x}$ frame interaction did not account for a significant proportion of the variance in cognitive processing, $R^{2}=.04, F(3,133)=1.62, p$ $=.19$ (Path $c_{2}$ in Figure 4 was not significant).

Recent statistics course. Younger women were asked if they had recently taken a statistics course (yes or no). Eighteen women indicated that they had recently taken a statistics course and 50 women indicated that they had not recently taken a statistics course. To examine whether recently taking a statistics course influenced susceptibility to the framing effect, a Univariate ANOVA was conducted with statistics course taken as the independent variable and treatment decision as the dependent variable. Treatment decision was a continuous variable. Results indicated that recently taking a statistics course did not affect treatment decision, $F$ (1, $67)=2.42, p=.12$, partial $\eta^{2}=.04$.

Decisions for breast cancer, general cancer, and non-cancer. Younger and older women rated on a 7-point Likert-type scale modified from Levin, Gaeth, Schreiber, and Lauriola (2002) the likelihood of choosing each option. The scale ranges from $1=$ Definitely Would Choose Treatment Option A to 7 = Definitely Would Choose Treatment Option B. The option "4" would be equivalent to the participant rating no preference between the two options. For both the positive and negative frame in the breast cancer domain and general cancer domains, a greater percentage of younger women chose option " 4 " than did older women. In the non-cancer domain, a greater percentage of younger women chose option " 4 " than did older women in the negative frame but not the positive frame (see Table 11). 


\section{Discussion}

\section{The Interaction of Age and Frame}

The hypothesis that frame would have more of an effect on older women's treatment decisions about breast cancer than on younger women's treatment decisions about breast cancer was supported. Frame influenced older women's decisions but did not influence younger women's decisions. When presented with a negatively framed treatment option (i.e., worded in terms of number of women who would die), older women endorsed riskier decisions than when presented with a positively framed treatment option (i.e., worded in terms of number of women who would live; see Figure 3). This is consistent with the findings from the classic framing study (Tversky \& Kahneman, 1979) that negatively framed messages lead to riskier decisions than positively framed messages. When options were worded in terms of number of deaths, older women reported that they would choose a treatment option that had a "chance" to save a greater number of persons instead of endorsing a treatment option that was reported to be a "sure thing" and would only save a small number of persons. However, for younger women, there was no main effect for frame; therefore, the hypothesis that frame would affect treatment decision, or that positively worded treatment options would lead to more risk averse decisions, was only partially supported.

For younger women, there was no significant difference in treatment decision regardless of the way in which the treatment options were worded. This finding is inconsistent with the literature. Very little research has examined the effect of age on frame; thus, most of the literature to date has reported the effect of frame on samples of younger adults. Although 
Kuhberger (1998) reports that effect sizes for frame are small to moderate, the majority of the literature on framing does find that the ways in which messages are worded influences decisions (see Kuhberger for a review). In the current study, frame did not influence younger women's decisions in any domain (i.e., breast cancer, general cancer, non-cancer); whereas, frame influenced older women's decisions in all domains (i.e., breast cancer, general cancer, noncancer). This inconsistent finding for younger women is interesting given the number of studies in the literature that show a framing effect. Perhaps this finding is due to experience with test taking in general. Undergraduate college students are offered extra credit to participate in research studies, and there are generally quite a few studies for which they can volunteer. Perhaps the younger women in the sample have participated in research before and have experience with the test taking process. However, it should be noted that the younger adults in other studies that show a framing effect may also have experience with general test taking and research participation. In addition, examination of the means (see Table 9) shows a slight trend toward the framing effect in the younger women in the same direction as that of the older women. Although a power analysis showed the sample to have sufficient power to detect medium effect sizes, Kuhberger (1998) states that the effects of frame are small to moderate. Perhaps a larger sample size would show an effect for frame for younger women.

The finding that the negative frame leads to riskier decisions for older women may be due to the idea of perceived time left to live, or future time perspective. According to Lang and Carstensen (2004) older individuals have a more limited future time perspective than do younger individuals. Future time perspective has been shown to influence health behaviors (Yarcheski, Mahon, Yarcheski, \& Cannella, 2004). Perhaps older women perceived that they had a more limited time left to live and therefore were more likely to endorse alternatives that would 
increase the chance of survival. In addition, perhaps, older adults feel that they have more things to accomplish before death so they would want to take chances that may increase survival.

The literature to date is inconsistent as to the effect of age on the susceptibility of the framing effect. Few studies have examined the interaction of age and frame. Mayhorn, Fisk, and Whittle (2002) examined the influence of age on medical and financial decisions and suggested that there are minimal age differences. McKee (2001) examined medical decision making and found that younger adults may be slightly more influenced by the frame than are older adults. The current study indicates that there are age differences in the susceptibility of frame; however, those differences may not be due to individual differences in cognitive capacity, processing, or experience, but may be due to a person's future time perspective. Future studies need to examine how frame influences the process of medical decision making in older adults, younger adults, and terminally ill patients in order to test the future time perspective hypothesis.

\section{Processing as a Mediator}

Type of cognitive processing was expected to mediate the significant interaction of age and frame. Although chronological age is often associated with poorer decision making and problem solving (Thorton \& Dumke, 2005), age is merely a marker, or proxy, variable. That is, age in itself does not cause changes in decision making but may be associated with another variable that does. Type of cognitive processing was expected to account for age differences in the effect of frame. The hypothesis was not supported. Type of cognitive processing (i.e., analytical and heuristic combined), did not affect treatment decisions (see Table 10). When analytic and heuristic processing were examined as dual processes, faith in intuition (i.e., heuristic processing) was not associated with treatment decisions. Need for cognition (i.e., analytical processing), however, was associated with treatment decision. 
Need for cognition. The hypothesis that frame would influence treatment decision in women with a low need for cognition to a greater extent than it would for women high in need for cognition was not supported. Need for cognition did significantly affect treatment decision; women who scored lower in need for cognition made riskier decisions regardless of how information was framed. However, there was not an interaction of frame and need for cognition; therefore, need for cognition did not moderate the relationship between frame and treatment decision (see Table 8). This is inconsistent with previous research that indicated need for cognition was negatively associated with susceptibility of framing effects (Chatterjee, Heath, Milberg, \& France, 2000; Simon et al., 2004; Smith \& Levin, 1998). There was trend towards significance for the interaction. Perhaps with a larger sample size the effect would emerge. Thus, of the variables examined, need for cognition seems the most promising predictor of treatment decisions.

There is a lack of measures available to examine heuristic and analytical processing. The literature to date lacks information on the construct validity of the Rational-Experiential Inventory (REI; Epstein, Pacini, Denes-Raj, \& Heier, 1996). Although the need for cognition scale (NFC; Cacioppo \& Petty, 1982) has been used numerous times, the version used in the REI was a shortened version with 19 items. There is a lack of information on the construct validity of the short version of the need for cognition scale used in the current study. Epstein and colleagues reported reliability of .77 for the need for cognition subscale and .80 for the faith in intuition (FI) subscale. In the current sample the need for cognition subscale also had reliability of .77, and the faith in intuition subscale also had reliability of .80. Although Epstein and colleagues state that the reliabilities are acceptable, one could expect higher reliabilities of scales with those number of items (i.e., NFC $=19$ items, FI $=12$ items). Future studies need to be 
conducted to examine the reliability and construct validity of the REI. Perhaps better measures to examine heuristic and analytical processing would indicate that cognitive processing influences susceptibility of the framing effect.

\section{Potential Moderators}

Cognitive ability. The hypothesis that women with low cognitive ability scores would be influenced more by the frame than would individuals who scored higher on cognitive ability was not supported. Neither cognitive ability; intelligence (i.e., the K-BIT composite score), fluid intelligence (i.e., the K-BIT matrices scores), nor crystallized intelligence (i.e., the K-BIT vocabulary score), was significantly related to treatment decision (see Table 7). The current sample was homogenous. The women were highly educated and had high scores on the cognitive ability measures; therefore, it was not possible to thoroughly examine the influence that cognitive ability would have on susceptibility to the framing effect due to restriction of range.

Experience. The hypothesis that frame would influence women with experience with breast cancer more than women with no experience of breast cancer was not supported. Experience was not significantly related to treatment decision (see Table 7). There were no younger adults in the sample who had personal experience with breast cancer, as was expected. It is rare for women under the age of 30 years to be diagnosed with breast cancer (ACS, 2005). Vicarious experience, or experience with breast cancer through a friend or family member's diagnosis, was also considered experience. Although both personal and vicarious experience have been shown to influence decision making with everyday problems (Patrick \& Strough, 2004); personal experience with a health problem may be conceptually different from vicarious experience with a health problem. Only a small number of older women reported personal 
experience with breast cancer $(N=11$ or $16.7 \%)$. A larger number of women with personal experience with breast cancer would have allowed a better examination of the effect of experience on treatment decisions.

Sensation seeking. The hypothesis that frame would not influence treatment decisions for women who scored extremely high (risk takers) or extremely low (risk avoiders) on sensation seeking was not supported. It was expected that general risk-taking propensity would override the influence of frame. That is, regardless of the way in which options were worded, women high in sensation seeking were expected to make riskier decisions; whereas, women low in sensation seeking were expected to make less risky decisions. Although younger women scored higher than older women on sensation seeking; it was not related to treatment decision (see Table 7). Perhaps general risk-taking propensity was not related to treatment decision due to the measure used to assess risk taking. There were very few scales available to measure general risk-taking propensity. The sensation-seeking measure was the best available at the time of the current study. The sensation seeking measure assessed risk taking in behaviors related to general activities (e.g., trip planning). There were no questions that dealt with risk taking in health behaviors. Perhaps risk taking in the domain of health may be qualitatively different than other domains (e.g., driving behavior); thus, perhaps a risk-taking scale that examines risky behavior specifically in the domain of health would yield different results.

\section{Limitations and Future Directions}

One limitation of the current study is the self-report nature of predicted behavior in response to a hypothetical vignette. Participants were asked to report on how they would react if they were faced with a similar situation. Although vignettes have been shown to be a useful way to examine problem-solving strategies (Berg, 1989; Blanchard-Fields, et al., 1995; Watson 
\& Blanchard-Fields, 1998), one cannot be certain how they will react unless faced with actual problem. Researchers may draw information from the research conducted using laboratory experimental methods (Johnson, 1993; Berg, Johnson, Meegan, \& Strough, 2004); however, reactions to real-world situation may differ from those in the laboratory. It is possible that older adults may react differently if they were actually faced with a similar situation. In addition, it is unlikely that women diagnosed with breast cancer would be presented with probability statistics worded the same as the vignettes used in the current study. Participants, particularly older women, stated that the vignettes were "difficult to answer." The wording of the treatment options may have been confusing, perhaps more confusing than the way options are presented to women in real-world situations. Future studies should examine the decision-making process of women actually diagnosed with the disease. The best strategy would be longitudinal studies that examine the ways in which individuals diagnosed with the disease make decisions throughout the course of the disease.

Another limitation is the use of a convenience sample. Individuals who volunteer to participate in studies tend to very healthy, more educated, and more motivated than the general population. In addition, this sample was highly homogenous. The sample consisted of highly educated, middle class, predominantly Caucasian women. Given the health disparities between races (Myers, Lewis \& Parker-Dominguez, 2003), older adults of different races and ethnic backgrounds would likely respond differently to the vignettes. Researchers should strive to oversample minorities in order to have a better understanding of racial and ethnic differences in medical decision making. In addition, in the future, a more diverse population with varying degrees of education should be examined. 
Conclusions

Findings from the current study indicate that the ways in which treatment options are worded influences the treatment options that older women endorse when presented with a breast cancer vignette. Health professionals can draw upon these results when developing ways to present various treatment options to patients. Women diagnosed with breast cancer also need to be aware of the effect that wording alone can have on treatment decisions. In addition, the results contribute to the literature that examines age differences in the framing effect. Studies that examine age differences in the framing effect need to be conducted using other designs and other types of wording options (e.g., survival curves) in order to gain a better understanding of the framing effect phenomena. 


\section{References}

Ackerman, P. L., Beier, M. E., \& Boyle, M. O. (2000). Individual differences in working memory within a nomological network of cognitive and perceptual speed abilities. Journal of Experimental Psychology, 131, 567-589.

American Cancer Society. (2005). Overview of Breast Cancer. Retrieved April 1, 2006, from http://www.cancer.org/docroot/CRI/CRI_2_1x.asp?dt=5.

Arnett, J. J. (1998). Risk behavior and family role transitions during the twenties. Journal of Youth and Adolescence, 27(3), 301-320.

Baltes, P. B., \& Baltes, M. M. (1990). Psychological perspectives on successful aging: The model of selective optimization with compensation. In P. B. Baltes \& M. M. Baltes (Eds.), Successful aging: Perspectives from the behavioral sciences (pp. 1-34). New York: Cambridge University Press.

Banks, S. M., Salvoey, P., Greener, S., Rothman, A. J., Moyer, A., Beauvais, J. \& Epel, E. (1995). The effects of message framing on mammography utilization. Health Psychology, 14(2), 178-184.

Baron, R. M., \& Kenny, D. A. (1986). The moderator-mediator variable distinction in social psychology research: conceptual, strategic, and statistical considerations. Journal of Personality and Social Psychology, 51(6), 1173-1182.

Berg, C. A., Johnson, M., Meegan, S. P., \& Strough, J. (2003). Collaborative problem solving interactions in young and old married couples. Discourse Processes, 35(1), 33-58.

Berg, C. A., Meegan, S. P., \& Klaczynski, P. (1999). Age and experiential differences in strategy generation and information requests for solving everyday problems. International Journal of Behavioral Development, 23(3), 615-639. 
Block, L. G., \& Keller, P. A. (1995). When to accentuate the negative: The effects of perceived efficacy and message framing on intentions to perform a health-related behavior. Journal of Marketing Research, XXXII, 192-203.

Cacioppo, J. T. \& Petty, R. E. (1982). The need for cognition. Journal of Personality and Social Psychology, 42, 116-131.

Chatterjee, S., Heath, T. B., Milberg, S. J., \& France, K. R. (2000). The differential processing of price in gains and losses: The effects of frame and need for cognition. Journal of Behavioral Decision Making, 13, 61-75.

Chaiken, S. (1987). The heuristic model of persuasion. In M. P. Zanna, J. M. Olsen, \& C. P. Herman (Eds.), Social Influence. Hillsdale, NJ: Erlbaum.

Cheng, S. \& Strough, J. (2004). A comparison of collaborative and individual everyday problem solving in younger and older adults. International Journal of Aging and Human Development, 58(3), 167-195.

Chi. M., Feltovich, P. J., \& Glaser, R. (1981). Categorization and conceptualization of physics problems by experts and novices. Cognitive Science, 5, 121-152.

Eagly, A. H., \& Chaiken, S. (1993). The Psychology of Attitudes. Orlando, FL: Harcourt Brace.

Engle, R. W. (2002). Working memory as executive attention. Current Directions in Psychological Science, 11, 19-23.

Epstein, S., Lipson, A., Holstein, C., \& Huh, E. (1992). Irrational reactions to negative outcomes: Evidence for two conceptual systems. Journal of Personality and Social Psychology, $62(2), 328-339$. 
Epstein, S., Pacini, R., Denes-Raj, V., \& Heier, H. (1996). Individual differences in intuitiveexperiential and analytical-rational thinking styles. Journal of Personality and Social Psychology, 71(2), 390-405.

Fagley, N. S., \& Miller, P. M. (1987). The effects of decision framing on choice of risky vs certain options. Organizational Behavior and Human Decision Processes, 39, 264-277.

Finucane, M. L., Slovic, P., Hibbard, J. H., Peters, E., Mertz, C. K., \& Macgregor, D. G. (2002). Aging and decision-making competence: An analysis of comprehension and consistency skills in older versus younger adults considering health plan options. Journal of Behavioral Decision Making, 15, 141-164.

Frisch, D. (1993). Reasons for framing effects. Organizational Behavior and Human Decision Processes, 54, 399-429.

Hammond, K. R. (1996). Human judgment and social policy. New York: Oxford University Press.

Holmbeck, G. N. (1997). Toward terminological, conceptual, and statistical clarity in the study of mediators and moderators: Examples from the child-clinical and pediatric literatures. Journal of Consulting and Clinical Psychology, 65, 599-610.

Johnson, M. M. S. (1990). Age differences in decision making: A process methodology for examining strategic information processing. Journal of Gerontology, 45, 75-78.

Johnson, M. M. S. (1993). Thinking about strategies: During, before, and after making a decision. Psychology and Aging, 8, 231-241.

Johnson, P. E. (1981). Cognitive models of medical problem solvers. In D. Connelly, E. Benson, \& D. Burke (Eds.), Clinical Decision Making and Laboratory Use. Minneapolis: University of Minneapolis Press. 
Johnson, P.E., Johnson, M. G., \& Little, R. K. (1984). Expertise in trial advocacy: Some considerations for inquiry into its nature and development. Campbell Law Review, 7, 119-143.

Kahneman, D. (2003). A perspective on judgment and choice: Mapping bounded rationality. American Psychologist, 58(9), 697-720.

Kahneman, D. \& Tversky, A. (1984). Choices, values, and frames. American Psychologist, 39(4), 341-350.

Kaufman, A.S. \& Kaufman, N.L. (1990). Kaufman Brief Intelligence Test. Circle Pines, MN: American Guidance Service.

Klaczynski, P., \& Robinson, B. (2000). Personal theories, intellectual ability, and epistemological beliefs: Adult age differences in everyday reasoning biases. Psychology and Aging, 15(3), 400-416.

Kuhberger, A. (1998). The influence of framing on risky decisions: A meta-analysis. Organizational Behavior and Human Decision Processes, 75(1), 23-55.

Kuvaas, B., \& Kaufmann, G. (2004). Impact of mood, framing, and need for cognition on decision makers' recall and confidence. Journal of Behavioral Decision Making, 17, 5974.

Lang, F. R. \& Carstensen, L. L. (2004). Time counts: future time perspective, goals, and social relationships. Psychology and Aging, 17, 125-139.

Lawton, M. P., Moss, M. S., Fulcomer, M., \& Kleban, M. H. (1982). A research and service oriented multilevel assessment instrument. Journal of Gerontology, 37, 91-99. 
Levin, I. P., Gaeth, G. J., Schreiber, J., \& Lauriola, M. (2002). A new look at framing effects: Distribution of effect sizes, individual differences, and independence of types and effects. Organizational Behavior and Human Decision Processes, 88(1), 411-429.

Lockenhoff, C. E., \& Carstensen, L. L. (2004). Socioemotional selectivity theory, aging, and health: the increasingly delicate balance between regulating emotions and making tough choices. Journal of Personality, 72(6), 1395-1424.

Loke, W., \& Tan, K. (1992). Effects of framing and missing information in expert and novice judgment. Bulletin of the Psychonomic Society, 30(3), 187-190.

Maheswaran, D., \& Meyers-Levy, J. (1990). The influence of message framing and issue involvement. Journal of Marketing Research, 27, 361-367.

Malloy, T. R., Wigton, R. S., Meeske, J., \& Tape, T. G. (1992). The influence of treatment descriptions on advance medical directive decisions. American Geriatrics Society, 40, 1255-1260.

Mather, M. \& Carstensen, L. L. (under review). Aging and memory for health care decisions. Stanford, CA: Stanford University.

Mayhorn, C. B., Fisk, A. D., \& Whittle, J. D. (2002). Decisions, decisions: Analysis of age, cohort, and time of testing on framing of risky decision options. Human Factors, 44(4), 515-521.

McKee, D. R. (2001). The effects of framing on younger and older adults' medical decisionmaking. Unpublished doctorial dissertation, West Virginia University.

McNeil, B., Pauker, S., Sox, H., Jr., \& Tversky, A. (1982). On the elicitation of preferences for alternative therapies. New England Journal of Medicine, 306, 1259-1262. 
Meyer, B. J. F., Russo, C., \& Talbot, A. (1995). Discourse comprehension and problem solving: Decisions about the treatment of breast cancer by women across the life span. Psychology and Aging, 10(1), 84-103.

Meyerowitz, B. \& Chaiken, S. (1987). The effect of message framing on breast self-examination attitudes, intentions, and behavior. Journal of Personality and Social Psychology, 52(3), 500-510.

Myers, H. F., Lewis, T. T., \& Parker-Dominguez, T. (2003). Stress, coping, and minority health. In G. Bernal, J. E. Trimble, A. K. Burlew, \& F. T. L. Leong (Eds.) Handbook of Racial and Ethnic Minority Psychology. Thousand Oaks, CA: Sage Publications.

Oberauer, K. (2000). Do we need two systems of reasoning? Behavioral and Brain Science, 23, 692-693.

Olekalns, M., \& Frey, B. F. (1994). Marketing forces, negotiator frames and transaction outcomes. European Journal of Social Psychology, 24, 403-416.

Osman, M. (2004). An evaluation of dual-process theories of reasoning. Psychonomic Bulletin and Review, 11, 988-1010.

Park, D. C. (1999). Aging and the controlled and automatic processing of medical information and medical intentions. In D. C. Park, R. W. Morrell, \& K. Shifren (Eds.), Processing of Medical Information in Aging Patients (pp. 3-23).

New Jersey: Lawrence Erlbaum Associates, Inc.

Petty, R. E. \& Cacioppo, J. T. (1986). Communication and persuasion: Central and peripheral routes to attitude change. New York: Springer-Verlag.

Patrick, J. H. \& Strough, J. (2004) Everyday problem solving: Experience, strategies, and behavioral intentions. Journal of Adult Development, 11, 9-19. 
Pierce, P. F. (1996). When the patient chooses: Describing unaided decisions in health care. Human Factors, 42, 278-287.

Rasmussen, S. (2005). Factors influencing anticipated decisions about sunscreen use. Journal of Health Psychology, 10, 585-595.

Reyna, V. F. (2004). How people make decisions that involve risk: A dual processes approach. Current Directions in Psychological Science, 13(2), 60-66.

Reyna, V. F. \& Brainerd, C. J. (1991). Fuzzy-trace theory and framing effects in choice: Gist extraction, truncation, and conversion. Journal of Behavioral Decision Making, 4, 249262.

Reyna, V. F. \& Brainerd, C. J. (1995). Fuzzy-trace theory: An interim synthesis. Learning and Individual Differences, 7, 1-75.

Rolison, M. R., \& Scherman, A. (2002). Factors influencing adolescents' decisions to engage in risk-taking behavior. Adolescence, 37(147), 585-596.

Rolinson, M. R., \& Scherman, A. (2003). College student risk-taking from three perspectives. Adolescence, 38(152), 689-704.

Rothman, A., \& Salovey, P. (1997). Shaping perceptions to motivate healthy behavior: The role of message framing. Psychological Bulletin, 121(1), 3-19.

Rybash, J. M., \& Roodin, P. A. (1989). The framing heuristic influences judgments about younger and older adults' decisions to refuse medical treatment. Applied Cognitive Psychology, 3, 171-180.

Salthouse, T., \& Babcock, R. (1990). Decomposing adult age differences in working memory. Developmental Psychology, 27, 763-776. 
Sharf, B. F., Stelljes, L. A., \& Gordon, H. S. (2005). 'A little bitty spot and I'm a big man': Patients' perspectives on refusing diagnosis for lung cancer. Psycho-oncology, 14, 636646.

Simon, A. F., Fagley, N. S., \& Halleran, J. G. (2004). Decision framing: Moderating effects of individual differences and cognitive processing. Journal of Behavioral Decision Making, 17, 77-93.

Slovic, P., Finucane, M. L., Peters, E., MacGregor, D. G. (2004). Risk as analysis and risk as feelings: some thoughts about affect, reason, risk, and rationality. Risk Analysis, 24, 311322.

Smith, S. M., \& Levin, I. P. (1995). Need for cognition and choice framing effects. Journal of Behavioral Decision Making, 9(4), 283-290.

Snyder, K. L. (2004). Factors influencing older adult collaboration on health problems. Unpublished master's thesis, West Virginia University.

Steginga, S. K., \& Occipininti, S. (2006). Dispositional optimism as a predictor of men's decision-related stress after localized prostate cancer. Health Psychology, 25, 135-143.

Tabachnick, B. G., \& Fidell, L. S. (2001). Using multivariate statistics (4 ${ }^{\text {th }}$ edition). Needham Heights, MA: Allyn \& Bacon.

Thorton, W. J. L., \& Dumke, H. A. (2005). Age differences in everyday problem-solving and decision-making effectiveness: A meta-analytic review. Psychology and Aging, 20(1), 85-99.

Tversky, A., \& Kahneman, D. (1979). Prospect theory: An analysis of decision under risk. Econometrica, 47(2), 263-292. 
Tversky, A., \& Kahneman, D. (1981). The framing decisions and the psychology of choice. Science, 211, 453-458.

U.S. Census. (2003). Women and men in the United States: March 2002. US Census Bureau. Vaeth, P. A. (1993). Women's knowledge about breast cancer. American Journal of Clinical Oncology, 16, 446-454.

Von Neumann, J., \& Morgenstern, O. (1947). Theory of games and economic behavior (2 ${ }^{\text {nd }}$ ed.). Princeton: Princeton University Press.

Watson, T. L., \& Blanchard-Fields, F. (1998). Thinking with your head and your heart: Age differences in everyday problem-solving strategy preferences. Aging, Neuropsychology and Cognition, 5, 225-240.

Weshler, D. (1977). Weschler Adult Intelligence Scale $\left(3^{\text {rd }}\right.$ ed). The Psychological Corporation: San Antonio: Harcourt Brace \& Company.

White, V. M., Wearing, A. J., \& Hill, D. J. (1994). Is the conflict model of decision making applicable to the decision to be screened for cervical cancer? A field study. Journal of Behavioral Decision Making, 7, 57-72.

Yarcheski, A., Mahon, N. E., Yarcheski, T. J., \& Cannella, B. L. (2004). A meta-analysis of predictors of positive health practice. Journal of Nursing Scholarship, 36, 102-108.

Yates, J. F., \& Patalano, A. L. (1999). Decision making and aging. In D. C. Park, R. W. Morrell, \& K. Shifren (Eds.), Processing of Medical Information in Aging Patients (pp. 31-54). New Jersey: Lawrence Erlbaum Associates, Inc.

Zuckererman, M. (1994). Behavioral Expressions and Biosocial Bases of Sensation Seeking. Massachusettes: Cambridge University Press. 
Zwahr, M. D. (1999). Cognitive processes and medical decisions. In D. C. Park, R. W. Morrell, \& K. Shifren (Eds.), Processing of Medical Information in Aging Patients (pp. 55-27). New Jersey: Lawrence Erlbaum Associates, Inc. 


\section{Table 1}

Cognitive Processing: Heuristic Versus Analytical (modified from Slovic, Finucane, Peters, \& MacGregor, 2004; p. 312).

\begin{tabular}{ll}
\hline Heuristic System & Analytic System \\
\hline $\begin{array}{l}\text { 1. Holistic } \\
\text { 2. Affective: pleasure-pain oriented }\end{array}$ & $\begin{array}{l}\text { 1. Analytic } \\
\text { 2. Logical: reason oriented (what is } \\
\text { sensible) }\end{array}$ \\
$\begin{array}{ll}\text { 3. Associationistic connections } & \text { 3. Logical connections } \\
\text { 4. Behavior mediated by "vibes" from past } & \text { 4. Behavior medicated by conscious } \\
\text { appraisal of events }\end{array}$ \\
$\begin{array}{ll}\text { 5. Encodes reality in concrete images, } \\
\text { metaphors, and narratives }\end{array}$ & $\begin{array}{l}\text { 5. Encodes reality in abstract symbols, } \\
\text { words, and numbers }\end{array}$ \\
$\begin{array}{ll}\text { 6. More rapid processing: oriented toward } \\
\text { immediate action }\end{array}$ & $\begin{array}{l}\text { 6. Slower processing: oriented toward } \\
\text { delayed action }\end{array}$ \\
$\begin{array}{l}\text { 7. Self-evidently valid: "experiencing is } \\
\text { believing" }\end{array}$ & $\begin{array}{l}\text { 7. Requires justification via logic and } \\
\text { evidence }\end{array}$ \\
\hline
\end{tabular}


Table 2

Descriptive Statistics for Women Who Did and Did Not Participate in the NIH-Funded Study

\begin{tabular}{|c|c|c|c|c|c|c|c|}
\hline & $\begin{array}{c}\text { From } \\
\text { NIH } \\
\text { Study } \\
\end{array}$ & & $\begin{array}{c}\text { Not From } \\
\text { NIH } \\
\text { Study } \\
\end{array}$ & & $\begin{array}{l}\text { Significance } \\
\text { Test }\end{array}$ & & \\
\hline & Mean & $S D$ & Mean & $S D$ & $F(1,133)$ & $p$ & $\begin{array}{l}n^{2} \\
\text { (partial) }\end{array}$ \\
\hline Education (years) & 13.63 & 2.01 & 13.66 & 1.19 & .01 & .94 & .00 \\
\hline $\begin{array}{l}\text { Knowledge about } \\
\text { Breast Cancer }\end{array}$ & 11.37 & 1.66 & 11.14 & 1.94 & .55 & .46 & .00 \\
\hline Self-Rated Health & 9.86 & 2.05 & 9.86 & 1.79 & .00 & .98 & .00 \\
\hline $\begin{array}{l}\text { Analytical } \\
\text { Processing }\end{array}$ & 2.94 & .46 & 2.93 & .42 & .00 & .93 & .00 \\
\hline Need for Cognition & 3.24 & .65 & 3.25 & .57 & .00 & .96 & .00 \\
\hline Faith in Intuition & 3.55 & .52 & 3.58 & .55 & .07 & .80 & .00 \\
\hline Sensation Seeking & 7.11 & 4.71 & 8.22 & 4.33 & 1.99 & .16 & .02 \\
\hline Intelligence & 104.17 & 12.27 & 101.93 & 10.94 & 1.20 & .28 & .01 \\
\hline $\begin{array}{l}\text { Crystallized } \\
\text { Intelligence }\end{array}$ & 104.68 & 11.91 & 100.71 & 10.53 & 4.05 & .05 & .03 \\
\hline Fluid Intelligence & 103.76 & 13.03 & 102.34 & 15.33 & .33 & .56 & .00 \\
\hline Income (\$) & 16973 & 17322 & 10862 & 12948 & 5.059 & .03 & .04 \\
\hline
\end{tabular}


Table 3

Experience with Breast Cancer for Women From and Not From the NIH Study

\begin{tabular}{|c|c|c|c|c|}
\hline & From NIH Study & Not From NIH Study & & \\
\hline & Percentage (from NIH) & Percentage (not from NIH) & $X^{2}$ & $p$ \\
\hline $\begin{array}{l}\text { Total } \\
\text { Experience }\end{array}$ & $56.6 \%$ & $72.4 \%$ & 3.56 & .06 \\
\hline $\begin{array}{l}\text { Personal } \\
\text { Experience }\end{array}$ & $52.6 \%$ & $70.7 \%$ & 1.25 & .26 \\
\hline $\begin{array}{l}\text { Vicarious } \\
\text { Experience }\end{array}$ & $47.4 \%$ & $29.3 \%$ & 4.49 & .05 \\
\hline
\end{tabular}


Table 4

Descriptive Information for Older and Younger Women

\begin{tabular}{|c|c|c|c|c|c|c|c|c|c|}
\hline & Total & & Older & Women & Younger & Women & & & \\
\hline & Mean & SD & Mean & SD & Mean & SD & $F(1,133)$ & $p$ & $\begin{array}{l}\eta^{2} \\
\text { (partial) }\end{array}$ \\
\hline Age (years) & 44.54 & 26.41 & & & & & & & \\
\hline Education (years) & 13.64 & 1.70 & 13.39 & 2.13 & 13.88 & 1.09 & 2.81 & .09 & .02 \\
\hline $\begin{array}{l}\text { Knowledge about } \\
\text { Breast Cancer }\end{array}$ & 11.27 & 1.79 & 11.11 & 1.87 & 11.43 & 1.70 & 1.08 & .30 & .01 \\
\hline Self-Rated Health & 9.86 & 1.94 & 9.25 & 2.12 & 10.44 & 1.54 & 13.72 & .00 & .09 \\
\hline Cognitive Processing & 3.37 & .42 & 2.91 & .47 & 2.95 & .41 & .23 & .63 & .00 \\
\hline Need for Cognition & 3.24 & .61 & 3.21 & .70 & 3.28 & .52 & .41 & .53 & .00 \\
\hline Faith in Intuition & 3.56 & .53 & 3.56 & .52 & 3.57 & .54 & .01 & .94 & .00 \\
\hline Sensation Seeking & 8.12 & 4.21 & 5.53 & 4.17 & 9.59 & 4.04 & 32.75 & .00 & .20 \\
\hline Intelligence & 103.20 & 11.72 & 104.15 & 13.96 & 102.27 & 9.05 & .85 & .36 & .01 \\
\hline $\begin{array}{l}\text { Crystallized } \\
\text { Intelligence }\end{array}$ & 102.96 & 11.47 & 105.18 & 12.92 & 100.81 & 9.44 & 5.02 & .03 & .04 \\
\hline Fluid Intelligence & 103.14 & 14.03 & 102.91 & 15.97 & 103.38 & 11.98 & .04 & .85 & .00 \\
\hline Income (\$) & 14382 & 15820 & 21969 & 17406 & 6911 & 9464 & 39.01 & .00 & .23 \\
\hline
\end{tabular}


Table 5

Experience with Breast Cancer for Older and Younger Women

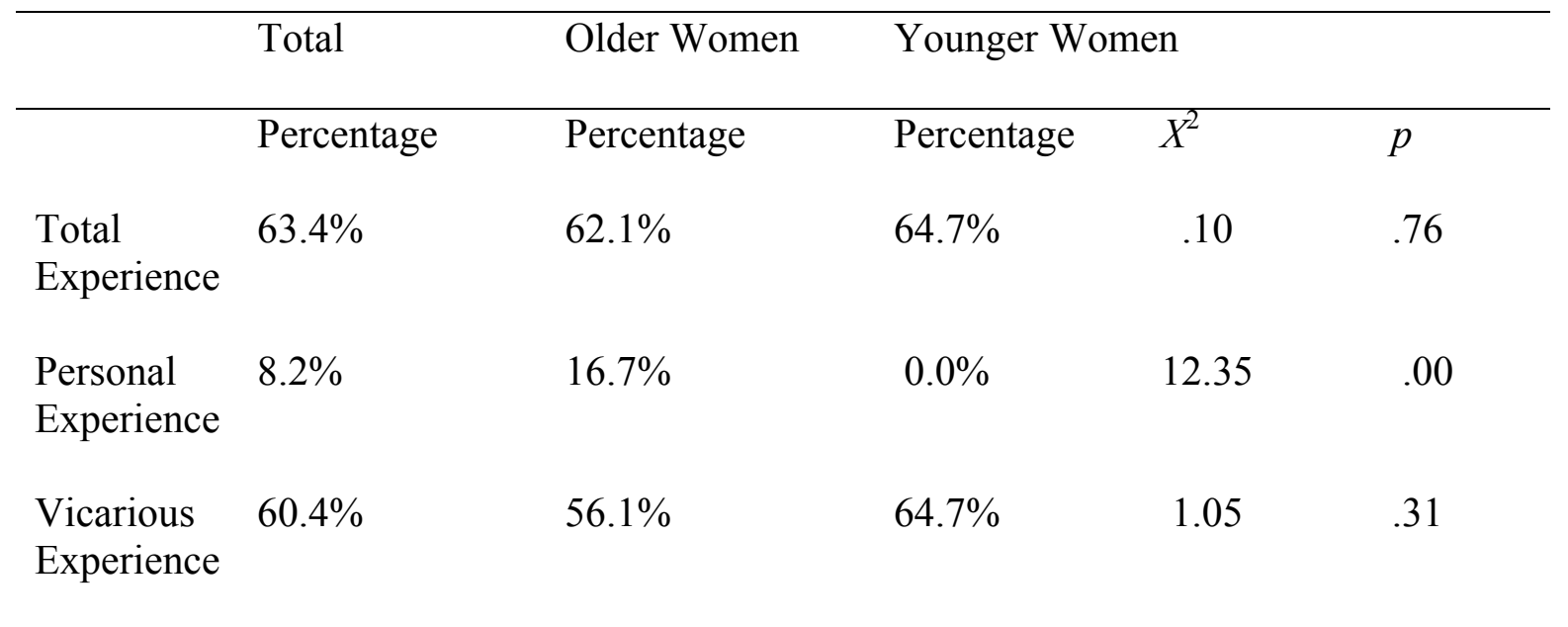


Table 6

Summary of Hierarchical Regression of Age and Frame on Treatment Choice $(\mathrm{N}=134)$

\begin{tabular}{lccccc}
\hline Variable & $B$ & $S E B$ & $\beta$ & $t$ & $p$ \\
\hline Step 1 & & & & & \\
Age & .01 & .01 & .10 & 1.21 & .23 \\
Frame & -1.34 & .30 & -.37 & -4.52 & .00 \\
Step 2 & & & & & \\
Age & .01 & .01 & .11 & 1.40 & .17 \\
Frame & -1.34 & .28 & -.37 & -4.75 & .00 \\
Age x Frame & -.04 & .01 & -.30 & -3.83 & .00 \\
\hline$R^{2}=.14$ for Step $1 ; \Delta R^{2}=.09$ for Step2.
\end{tabular}


Table 7

Summary of Separate Linear Regressions of Cognitive Ability, Experience, and Sensation Seeking Predicting Treatment Choice $(\mathrm{N}=134)$

\begin{tabular}{lcccccc}
\hline Variable & $B$ & $S E B$ & $\beta$ & $t$ & $p$ & $R^{2}$ \\
\hline Intelligence & .01 & .01 & .09 & 1.52 & .13 & .01 \\
$\begin{array}{l}\text { Crystallized } \\
\text { Intelligence }\end{array}$ & .03 & .01 & .17 & .60 & .06 & .03 \\
$\begin{array}{l}\text { Fluid } \\
\text { Intelligence }\end{array}$ & .01 & .01 & .06 & .68 & .50 & .06 \\
Experience & -.13 & .33 & -.09 & -.38 & .70 & .00 \\
Sensation & -.04 & .04 & -.19 & -1.00 & .32 & .01 \\
Seeking & & & & & & \\
\end{tabular}


Table 8

Summary of Hierarchical Regression of Frame and Need for Cognition on Treatment Choice $(\mathrm{N}=134)$

\begin{tabular}{|c|c|c|c|c|c|}
\hline Variable & $\mathrm{B}$ & SE B & $\beta$ & $t$ & $p$ \\
\hline \multicolumn{6}{|l|}{ Model 1} \\
\hline Frame & -1.29 & .24 & -.35 & -4.47 & .00 \\
\hline Need for Cognition & -.45 & .30 & -.15 & -1.86 & .06 \\
\hline \multicolumn{6}{|l|}{ Model 2} \\
\hline Frame & -1.29 & .30 & -.35 & -4.36 & .00 \\
\hline Need for Cognition & -.45 & .24 & -.15 & -1.85 & .07 \\
\hline Frame $\mathrm{x}$ Need for Cognition & .22 & .49 & .04 & .455 & .65 \\
\hline
\end{tabular}


Table 9

Older and Younger Women's Means Decision (Standard Error) in All Domains

\begin{tabular}{lllllllllll}
\multicolumn{1}{c}{ Older } & \multicolumn{9}{c}{ Younger } \\
& Women & & \multicolumn{3}{c}{ Women } \\
& Positive & Negative & Total & Positive & Negative & Total & Positive & Negative & Total \\
\hline \multirow{3}{*}{ Breast } & $\begin{array}{l}\text { Frame } \\
\text { Cancer }\end{array}$ & $\begin{array}{l}\text { Frame } \\
\text { (.21) }\end{array}$ & $4.97^{\mathrm{a}}$ & 3.89 & 3.68 & 3.87 & $3.78_{\mathrm{d}}$ & 3.25 & 4.42 & 3.83 \\
& $(.20)$ & $(.15)$ & $(.21)$ & $(.19)$ & $(.15)$ & $(.15)$ & $(.14)$ & $(.11)$ \\
General & $3.20^{\mathrm{b}}$ & $4.77^{\mathrm{b}}$ & 3.99 & 3.71 & 4.11 & 3.91 & 3.46 & 4.44 & 3.95 \\
Cancer & $(.20)$ & $(.20)$ & $(.16)$ & $(.20)$ & $(.19)$ & $(.16)$ & $(.14)$ & $(.14)$ & $(.11)$ \\
& & & & & & & & & \\
Non- & $3.77^{\mathrm{c}}$ & $4.77^{\mathrm{c}}$ & 4.27 & 4.18 & 4.29 & $4.24_{\mathrm{d}}$ & 3.97 & 4.53 & 4.25 \\
Cancer & $(.22)$ & $(.21)$ & $(.17)$ & $(.21)$ & $(.20)$ & $(.17)$ & $(.15)$ & $(.15)$ & $(.12)$ \\
Total & 3.26 & 4.84 & 4.05 & 3.86 & 4.09 & 3.98 & 3.56 & 4.47 & 4.01 \\
& $(.16)$ & $(.15)$ & $(.13)$ & $(.16)$ & $(.15)$ & $(.12)$ & $(.12)$ & $(.11)$ & $(.09)$ \\
\hline
\end{tabular}

Note: Matching letters in each row equals significant difference. Matching letters in each column equals significant difference. 
Table 10

Summary of Separate Linear Regressions of Cognitive Processing, Need for Cognition, and Faith in Intuition on Treatment Choice $(\mathrm{N}=134)$

\begin{tabular}{lcccccc}
\hline Variable & B & SE B & $\beta$ & $t$ & $p$ & $R^{2}$ \\
\hline Cognitive Processing & -.69 & .36 & -.16 & -1.90 & .06 & .16 \\
Need for Cognition & -.54 & .26 & -.18 & -2.11 & .04 & .18 \\
Faith in Intuition & .05 & .30 & .02 & .20 & .85 & .02 \\
\hline
\end{tabular}


Table 11

Frequencies of Treatment Decision Ratings for the Total Sample and Older and Younger Women

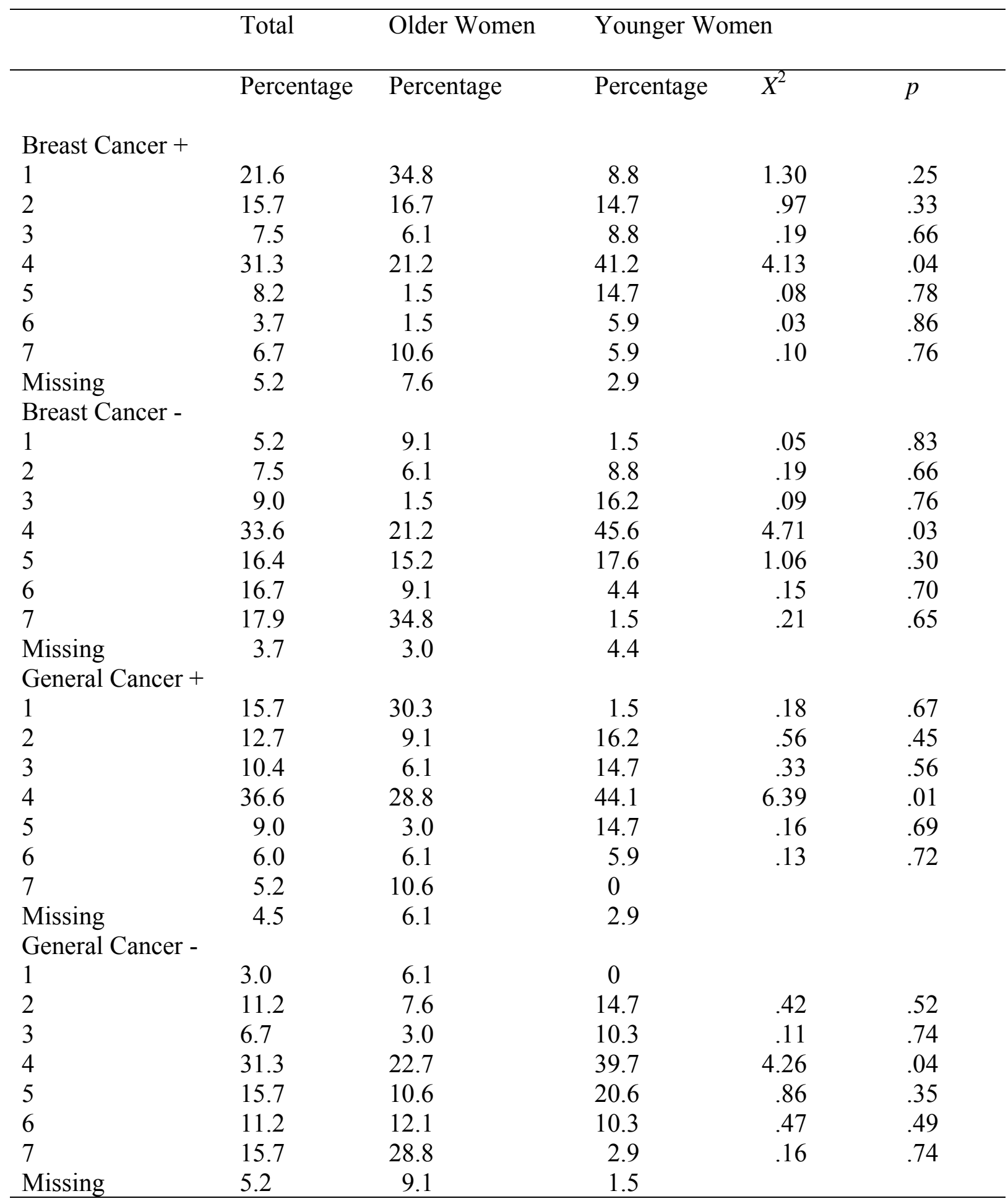

Table continues on next page 
Table 11 continued

\begin{tabular}{lrrrrr}
\hline Non-cancer + & & & & & \\
1 & 10.4 & 18.2 & 2.9 & .20 & .65 \\
2 & 9.7 & 13.6 & 5.9 & .30 & .58 \\
3 & 11.9 & 3.0 & 20.6 & .24 & .63 \\
4 & 28.4 & 27.3 & 29.4 & 3.68 & .06 \\
5 & 13.4 & 9.1 & 17.6 & .62 & .43 \\
6 & 9.0 & 1.5 & 16.2 & .09 & .76 \\
7 & 11.2 & 19.7 & 2.9 & .22 & .64 \\
Missing & 6.0 & 7.6 & 4.4 & & \\
Non-cancer- & & & & & \\
1 & 4.5 & 9.1 & 0 & .12 & .73 \\
2 & 6.0 & 4.5 & 7.4 & .25 & .62 \\
3 & 9.7 & 4.5 & 14.7 & 4.59 & .47 \\
4 & 31.3 & 28.8 & 33.8 & .52 & .45 \\
5 & 14.2 & 6.1 & 22.1 & .59 & \\
6 & 13.4 & 12.1 & 14.7 & & \\
7 & 17.9 & 31.8 & 4.4 & 2.9 & \\
Missing & 3.0 & 3.0 & 2.9 & \\
\hline
\end{tabular}


Figure 1. Mediator Model (from Baron \& Kenny, 1986; p. 1176)

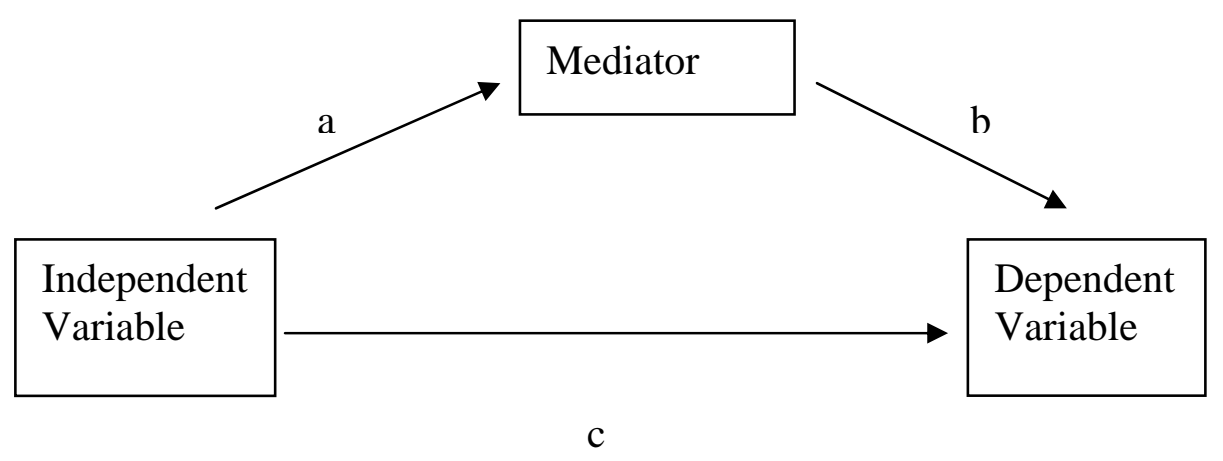


Figure 2. Moderator Model (from Baron \& Kenny, 1986; p. 1174)

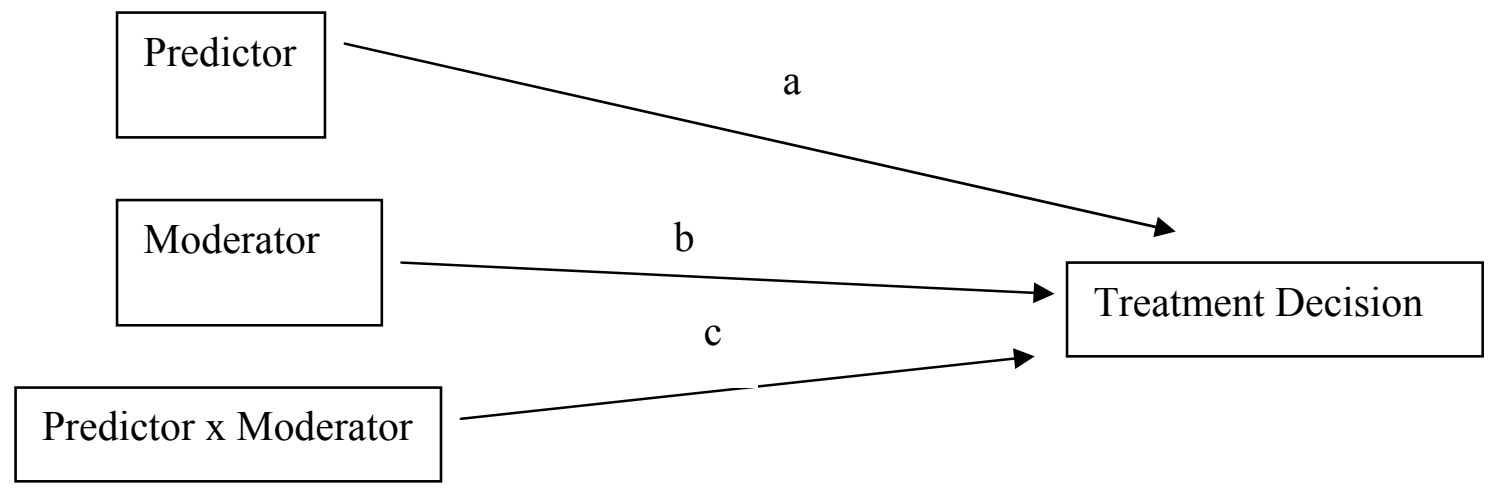


Figure 3. Older Women: Age x Frame Interaction

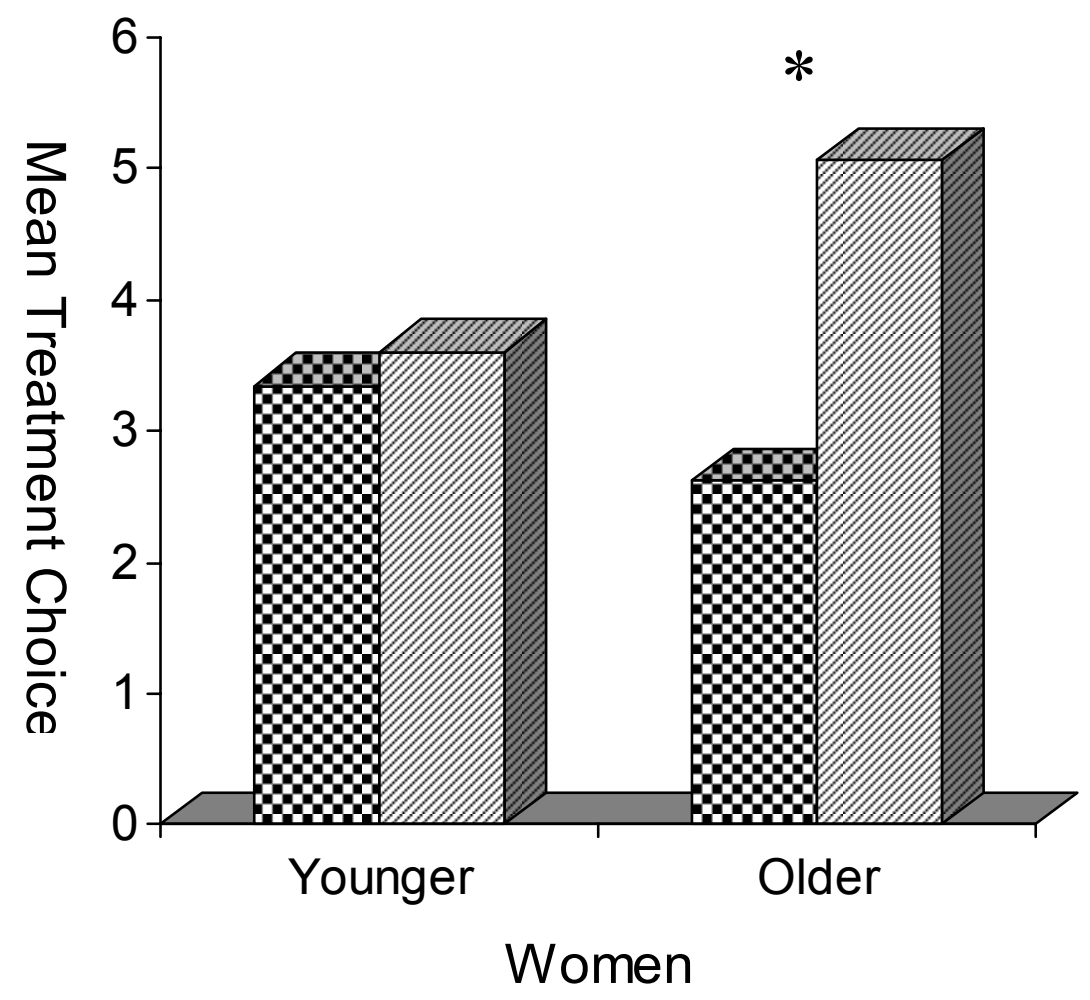

Positive Frame 囚 Negative Frame 
Figure 4. Mediated Moderation Model (from Baron \& Kenny, 1986; p. 1179)

$b_{1}$

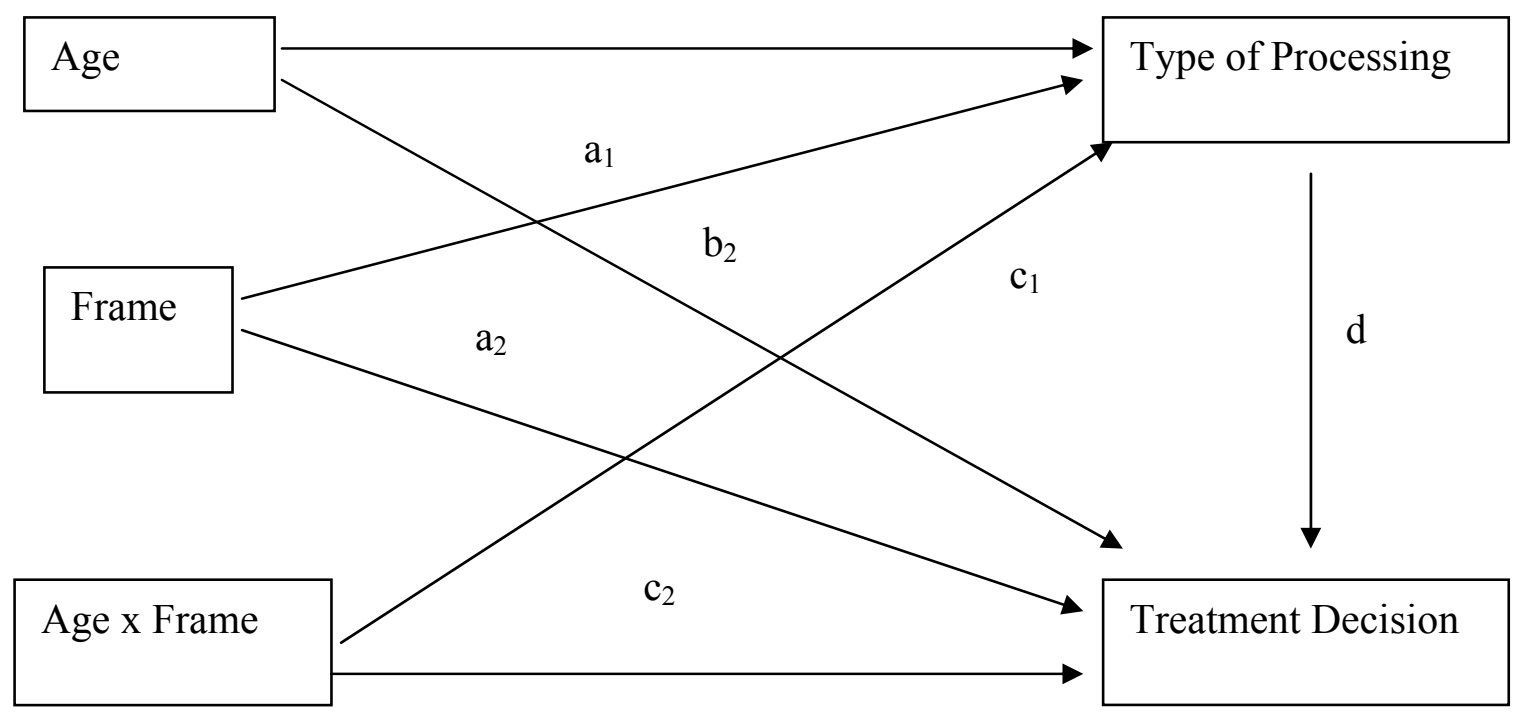


Figure 5. Older Women's Decisions in Each Domain

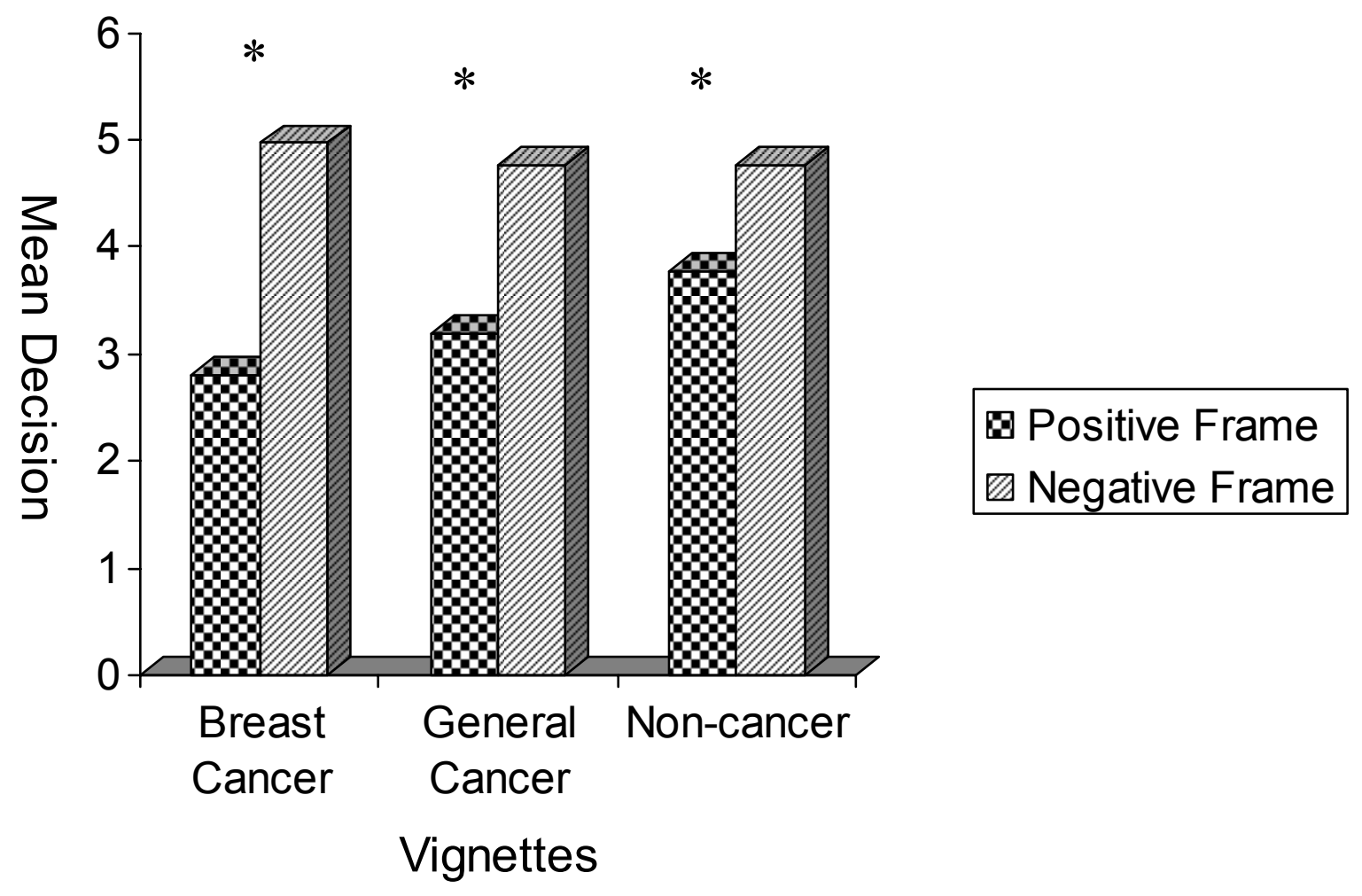




\section{Appendix A: Decision-making Questionnaire}

Please think about the following situation.

You have been diagnosed with a rare form breast cancer. Otherwise, you are in an excellent state of health. It is expected that 600 women will be diagnosed with this type of breast cancer this year. There are two experimental treatment programs that involve equal amounts of both drug therapy and radiation. Your physician describes the calculated odds of being cured for each treatment program.

Please list all of the different ways that you would deal with the situation. That is, write as many different solutions as you can think of. Please put each solution on a different line. Please place an " $X$ " next to the solution that you think is the BEST. 
Would you want to talk to someone about the situation? (circle one) Yes No

If yes, who would you talk to? Please list your relationship with this person. For example: friend, spouse, etc. List all of the people you would talk to. Please put each on a separate line. 


\section{Please think about the situation again.}

You have been diagnosed with a rare form breast cancer. Otherwise, you are in an excellent state of health. It is expected that 600 women will be diagnosed with this type of breast cancer this year. There are two experimental treatment programs that involve equal amounts of both drug therapy and radiation. Your physician describes the calculated odds of being cured for each treatment program.

A) In treatment program A, 200 women will be cured.

B) In treatment program $B$, there is a $1 / 3$ chance that 600 women will be cured and a $2 / 3$ chance that no women will be cured.

Please rate the likelihood of choosing a treatment option (circle one).

\begin{tabular}{|c|c|c|c|c|c|c|}
\hline $\begin{array}{c}1 \\
\text { Definitively } \\
\text { Would } \\
\text { Choose } \\
\text { Treatment } \\
\text { Option A }\end{array}$ & 2 & 3 & 4 & 5 & 6 & $\begin{array}{c}7 \\
\text { Definitively } \\
\text { Would } \\
\text { Choose } \\
\text { Treatment } \\
\text { Option B }\end{array}$ \\
\hline
\end{tabular}




\section{Please think about the situation again.}

You have been diagnosed with a rare form breast cancer. Otherwise, you are in an excellent state of health. It is expected that 600 women will be diagnosed with this type of breast cancer this year. There are two experimental treatment programs that involve equal amounts of both drug therapy and radiation. Your physician describes the calculated odds of being cured for each treatment program.

A) In treatment program A, 400 women will die.

B) In treatment program $B$, there is a $1 / 3$ chance that no women will die, and a $2 / 3$ chance that 600 women will die.

Please rate the likelihood of choosing a treatment option (circle one).

\begin{tabular}{|c|c|c|c|c|c|c|}
\hline 1 & 3 & 4 & 5 & 6 & 7 \\
$\begin{array}{c}\text { Definitively } \\
\text { Would }\end{array}$ & & & & & & $\begin{array}{c}\text { Definitively } \\
\text { Would } \\
\text { Choose }\end{array}$ \\
$\begin{array}{c}\text { Treatment } \\
\text { Option A }\end{array}$ & & & & & & $\begin{array}{c}\text { Choose } \\
\text { Treatment } \\
\text { Option B }\end{array}$ \\
\hline
\end{tabular}




\section{Please think about the following situation.}

The National Institute for Cancer has two possible treatments for cancer, which could become standard treatments across the country.

There are adequate resources to implement only 1 treatment program.

A. If treatment 1 is adopted, of every 600 people who get cancer 200 will be cured.

B. If treatment 2 is adopted, there is a $1 / 3$ chance that 600 people will be saved and a $2 / 3$ chance that no people will be cured.

Please rate the likelihood of choosing a treatment option (circle one).

\begin{tabular}{|c|c|c|c|c|c|c|}
\hline 1 & 3 & 4 & 5 & 6 & 7 \\
$\begin{array}{c}\text { Definitively } \\
\text { Would }\end{array}$ & & & & & $\begin{array}{c}\text { Definitively } \\
\text { Would } \\
\text { Choose }\end{array}$ \\
$\begin{array}{c}\text { Treatment } \\
\text { Option A }\end{array}$ & & & & & & $\begin{array}{c}\text { Choose } \\
\text { Treatment } \\
\text { Option B }\end{array}$ \\
\hline
\end{tabular}


Please think about the following situation.

A ship hits a sunken barge and is sinking in the middle of the ocean. There are 600 people on the ship. Their lives are in danger. Two options are proposed. Assume that the exact estimates of the consequences of the options are as follows:

A. If option A is adopted, 200 people will be saved.

B. If option B is adopted, there is a $1 / 3$ chance that 600 people will be saved and a $2 / 3$ chance that none will be saved.

Please rate the likelihood of choosing an option (circle one).

\begin{tabular}{|c|c|c|c|c|c|c|}
\hline 1 & 3 & 4 & 5 & 6 & 7 \\
$\begin{array}{c}\text { Definitively } \\
\text { Would }\end{array}$ & & & & & & $\begin{array}{c}\text { Definitively } \\
\text { Would } \\
\text { Choose }\end{array}$ \\
Option A & & & & & & $\begin{array}{c}\text { Choose } \\
\text { Option B }\end{array}$ \\
\hline
\end{tabular}




\section{Please think about the following situation.}

The National Institute for Cancer has two possible treatments for cancer, which could become standard treatments across the country.

There are adequate resources to implement only 1 treatment program.

A. If treatment 1 is adopted, of every 600 people who get cancer 400 will die.

B. If treatment 2 is adopted, there is a $1 / 3$ chance that no people will die and a $2 / 3$ chance that 600 people will die.

Please rate the likelihood of choosing a treatment option (circle one).

\begin{tabular}{|c|c|c|c|c|c|c|}
\hline 1 & 3 & 4 & 5 & 6 & 7 \\
$\begin{array}{c}\text { Definitively } \\
\text { Would }\end{array}$ & & & & & & $\begin{array}{c}\text { Definitively } \\
\text { Would } \\
\text { Choose }\end{array}$ \\
$\begin{array}{c}\text { Treatment } \\
\text { Option A }\end{array}$ & & & & & & $\begin{array}{c}\text { Choose } \\
\text { Treatment } \\
\text { Option B }\end{array}$ \\
\hline
\end{tabular}




\section{Please think about the following situation.}

A ship hits a sunken barge and is sinking in the middle of the ocean. There are 600 people on the ship. Their lives are in danger. Two options for saving the passengers are proposed. Assume that the exact estimates of the consequences of the options are as follows:

A. In option A, 400 people will die.

B. In option $B$, there is a $1 / 3$ chance that no people will die, and a $2 / 3$ chance that 600 people will die.

Please rate the likelihood of choosing an option (circle one).

\begin{tabular}{|c|c|c|c|c|c|c|}
\hline 1 & 3 & 4 & 5 & 6 & 7 \\
$\begin{array}{c}\text { Definitively } \\
\text { Would }\end{array}$ & & & & & & $\begin{array}{c}\text { Definitively } \\
\text { Would } \\
\text { Choose }\end{array}$ \\
Option A & & & & & & $\begin{array}{c}\text { Choose } \\
\text { Option B }\end{array}$ \\
\hline
\end{tabular}




\section{Information about you}

1. Sex (circle one)

Male Female

2. Age years Date of Birth:

3. Race

African American

Asian

Caucasian

Hispanic

Other Specify

4. Highest Education

High school

Some college

4-year college degree

Graduate degree

5. What city/town and state are you a permanent resident of?

City/town

State

6. Your current yearly income

Less than $\$ 10,000$

$\$ 10,001-\$ 20,000$

$\$ 20,001-\$ 30,000$

$\$ 30,001-\$ 40,000$

$\$ 40,001-\$ 50,000$

$\$ 50,001-\$ 60,000$

More than $\$ 60,000$

7. Number of children (living or deceased)

8. Religious affiliation

Jewish

Protestant

Roman Catholic

Other (specify

None 
9. What is your marital status, are you:

1.) Married (indicate number of years married

2.) Not married, but living together as married (indicate number of years

3.) Widowed (indicate number of years married and number of years widowed

4.) Divorced (indicate number of years married and number of years divorced

5.) Never married

6.) Other

10. Do you currently live:
a. alone
b. with a spouse
c. with a friend/not related
d. with relatives (specify relationship
e. with others (specific relationship

11. What kind of work have you done most of your life?

For what kind of business, company or agency is that?

12. What is your current work status? Are you:
a. Employed full time
b. Employed part time
c. Retired
d. Unemployed
e. Homemaker
f. Other (specify

13. How long have you been a patient of your family physician?

Years

Months

14. What is the gender of your physician? (circle one) Male Female

15. How comfortable are you speaking to your physician about your health? (circle one)

\begin{tabular}{|c|c|c|c|c|}
\hline 1 & 2 & 3 & 4 & 5 \\
$\begin{array}{c}\text { Not At All } \\
\text { Comfortable }\end{array}$ & $\begin{array}{c}\text { Somewhat } \\
\text { Uncomfortable }\end{array}$ & Neutral & Comfortable & $\begin{array}{c}\text { Very } \\
\text { Comfortable }\end{array}$ \\
\hline
\end{tabular}


16. How comfortable would you feel asking for a $2^{\text {nd }}$ opinion?

\begin{tabular}{|c|c|c|c|c|}
\hline 1 & 2 & 3 & 4 & 5 \\
Not At All & Somewhat & Neutral & Comfortable & $\begin{array}{c}\text { Very } \\
\text { Comfortable }\end{array}$ \\
\hline
\end{tabular}

17. Think about the past year, how many times did you go to your doctor?

Number of times

18. Health Insurance Information

\begin{tabular}{|l|c|c|}
\hline $\begin{array}{l}\text { Do you have health } \\
\text { insurance? }\end{array}$ & Yes & No \\
\hline $\begin{array}{c}\text { If yes, is your health care } \\
\text { provided by private } \\
\text { insurance? }\end{array}$ & Yes & No \\
\hline $\begin{array}{c}\text { Is your health insurance } \\
\text { related to a current or } \\
\text { former employer? }\end{array}$ & Yes & No \\
\hline $\begin{array}{c}\text { Do you receive benefits } \\
\text { from Medicare? }\end{array}$ & Yes & No \\
\hline $\begin{array}{c}\text { Do you receive benefits } \\
\text { from Medicaid? }\end{array}$ & Yes & No \\
\hline $\begin{array}{c}\text { Do you have prescription } \\
\text { drug benefits? }\end{array}$ & Yes & No \\
\hline $\begin{array}{c}\text { Are you a member of an } \\
\text { HMO? }\end{array}$ & Yes & NO \\
\hline
\end{tabular}

19. How much choice do you have in choosing a physician?

\begin{tabular}{|c|c|c|c|c|}
\hline $\begin{array}{c}\text { No Choice At } \\
\text { All }\end{array}$ & 2 & 3 & 4 & 5 \\
Little Choice & Some Choice & $\begin{array}{c}\text { Mostly Up To } \\
\text { Me }\end{array}$ & $\begin{array}{c}\text { Totally Up To } \\
\text { Me }\end{array}$ \\
\hline
\end{tabular}


20. How easy is it for you to get to your doctor? (circle one)

\begin{tabular}{|c|c|c|c|c|c|c|}
\hline 1 & 2 & 3 & 4 & 5 & 6 & 7 \\
$\begin{array}{c}\text { Extremely } \\
\text { Difficult }\end{array}$ & Difficult & $\begin{array}{c}\text { Somewhat } \\
\text { Difficult }\end{array}$ & $\begin{array}{c}\text { Neutral } \\
\text { Fairly } \\
\text { Easy }\end{array}$ & Easy & $\begin{array}{c}\text { Extremely } \\
\text { Easy }\end{array}$ \\
\hline
\end{tabular}

21. Please list all health-related conditions from which you currently suffer.

22. About how many days have you spent in the hospital in the past 12 months?

Number of days

23. About how many days during the past twelve months have you been sick in bed all or most of the day?

Number of days

24. Are you currently taking any prescription drugs? Yes No

If yes, please list what prescriptions and why you are taking them.

25. Are you currently taking any over the counter drugs? Yes No If yes, please list what and why you are taking them.

26. Do you smoke cigarettes or cigars? (circle one) Yes No 
27. Personal experience with breast cancer

\begin{tabular}{|c|c|c|c|c|}
\hline $\begin{array}{l}\text { Have you ever been } \\
\text { diagnosed with breast } \\
\text { cancer? (circle one) }\end{array}$ & Yes & No & & \\
\hline $\begin{array}{l}\text { If yes, what month and year } \\
\text { were you diagnosed? }\end{array}$ & Month_ & Year & & \\
\hline $\begin{array}{l}\text { What treatment did you } \\
\text { receive? (circle all that } \\
\text { apply) }\end{array}$ & Radiation & Surgery & Chemotherapy & $\begin{array}{l}\text { Other } \\
\text { (specify) }\end{array}$ \\
\hline $\begin{array}{l}\text { Is the cancer cured or in } \\
\text { remission? (circle one) }\end{array}$ & Yes & No & & \\
\hline
\end{tabular}


28. Personal experience with cancer

\begin{tabular}{|c|c|c|c|c|}
\hline $\begin{array}{l}\text { Have you ever been } \\
\text { diagnosed with another } \\
\text { type of cancer? (circle one) }\end{array}$ & Yes & No & & \\
\hline If yes, what type of cancer? & & & & \\
\hline $\begin{array}{l}\text { What month and year were } \\
\text { you diagnosed? }\end{array}$ & Month & Year & & \\
\hline $\begin{array}{l}\text { What treatment did you } \\
\text { receive? (circle all that } \\
\text { apply) }\end{array}$ & Radiation & Surgery & Chemotherapy & $\begin{array}{l}\text { Other } \\
\text { (specify) }\end{array}$ \\
\hline $\begin{array}{l}\text { Is the cancer cured or in } \\
\text { remission? (circle one) }\end{array}$ & Yes & No & & \\
\hline
\end{tabular}


29. Family member/friend experience with breast cancer

\begin{tabular}{|l|l|l|l|l|l|}
\hline $\begin{array}{l}\text { Do you any close friends or } \\
\text { family members who have } \\
\text { been diagnosed with breast } \\
\text { cancer? (circle one) }\end{array}$ & Yes & No & & \\
\hline $\begin{array}{l}\text { What is your relationship } \\
\text { with that person? }\end{array}$ & Example:_friend & & & \\
\hline $\begin{array}{l}\text { How close do you feel to } \\
\text { that person? }\end{array}$ & Not Very Close & Somewhat Close & Close & Very Close & \\
\hline $\begin{array}{l}\text { When was this person } \\
\text { diagnosed with breast } \\
\text { cancer? (circle one) }\end{array}$ & Earlier than 1970 & $1970-1980$ & $1980-1990$ & $1990-2000$ & $2000-$ Present \\
\hline $\begin{array}{l}\text { How involved were you in } \\
\text { this person's medical care? }\end{array}$ & Not Very Involved & Somewhat Involved & $\begin{array}{c}\text { Involved } \\
\text { Is }\end{array}$ & $\begin{array}{c}\text { Very } \\
\text { Involved }\end{array}$ & \\
\hline $\begin{array}{l}\text { Is the cancer cured or in } \\
\text { remission? (circle one) }\end{array}$ & Yes & No & & \\
\hline
\end{tabular}

